\title{
Evidence for Metabotropic Glutamate Receptor Activation in the Induction of Depolarization-Induced Suppression of Inhibition in Hippocampal CA1
}

\author{
Wade Morishita, Sergei A. Kirov, and Bradley E. Alger \\ Department of Physiology, University of Maryland School of Medicine, Baltimore, Maryland 21201
}

Depolarization-induced suppression of inhibition (DSI) is a transient reduction of $\mathrm{GABA}_{\mathrm{A}}$ receptor-mediated IPSCs that is mediated by a retrograde signal from principal cells to interneurons. Using whole-cell recordings, we tested the hypothesis that mGluRs are involved in the DSI process in hippocampal CA1, as has been proposed for cerebellar DSI. Group II mGluR agonists failed to affect either evoked monosynaptic IPSCs or DSI, and forskolin, which blocks cerebellar DSI, did not affect CA1 DSI. Group I and group III mGluR agonists reduced IPSCs, but only group I agonists occluded DSI. (S)-MCPG blocked

Depolarization-induced suppression of inhibition (DSI) is a phenomenon seen in both hippocampal CA1 pyramidal cells (Pitler and Alger, 1992, 1994; Alger et al., 1996; Morishita and Alger, 1997a) and cerebellar Purkinje cells (Llano et al., 1991; Vincent et al., 1992; Vincent and Marty, 1993). It involves the transient ( $\sim 1 \mathrm{~min}$ ) suppression of $\mathrm{GABA}_{\mathrm{A}}$ receptor-mediated $\left(\mathrm{GABA}_{\mathrm{A}} \mathrm{R}\right.$ mediated) IPSCs impinging on these cells after depolarization of their membranes that is sufficient to open voltage-gated $\mathrm{Ca}^{2+}$ channels. Despite the clearly postsynaptic locus of induction of DSI, the actual suppression of inhibition occurs via a presynaptic mechanism. Many experiments have led to the conclusion that the quantal content of $\mathrm{GABA}_{\mathrm{A}} \mathrm{R}$-mediated IPSCs is reduced, with no evidence of a decrease in postsynaptic $\mathrm{GABA}_{\mathrm{A}} \mathrm{R}$ responsiveness-neither iontophoretic $\mathrm{GABA}_{\mathrm{A}} \mathrm{R}$-mediated responses nor quantal size is reduced-during DSI. Taken together, the postsynaptic site of induction plus the presynaptic site of expression strongly imply that a retrograde signal must pass between the principal cells and their interneurons (Alger and Pitler, 1995).

It has been suggested recently that glutamate, released from Purkinje cells and acting on a presynaptic group II mGluR on the GABA-releasing basket cells, is the retrograde messenger for DSI in the cerebellum (Glitsch et al., 1996). Supporting evidence includes the findings that the specific mGluR agonist DCG-IV mimics and occludes DSI and that the mGluR antagonist L-AP3 reduces DSI [for review of mGluR pharmacology, see Pin and Duvoisin (1995)]. Group II mGluRs (mGluR2 and mGluR3)

Received Feb. 6, 1998; revised April 10, 1998; accepted April 16, 1998.

This work was supported by National Institutes of Health Grants NS30219 and NS22010 to B.E.A. We thank E. Elizabeth for expert typing and editorial assistance. We also thank F. Le Beau, R. Lenz, S. Mason, L. Martin, and N. Varma for their comments on a draft of this manuscript.

W.M. and S.A.K. contributed equally to this work.

Correspondence should be addressed to Dr. B. E. Alger, Department of Physiology, University of Maryland School of Medicine, 655 West Baltimore Street, Baltimore, MD 21201.

Dr. Kirov's present address: Children's Hospital, Department of Neurology, Harvard Medical School, 300 Longwood Avenue, Room 211, Boston, MA 02115.

Copyright (C) 1998 Society for Neuroscience $0270-6474 / 98 / 184870-13 \$ 05.00 / 0$
(1S,3R)-ACPD-induced IPSC suppression and markedly reduced DSI, whereas group III antagonists had no effect on DSI. Many other similarities between DSI and the (1S,3R)-ACPDinduced suppression of IPSCs also were found. Our data suggest that a glutamate-like substance released from pyramidal cells could mediate CA1 DSI by reducing GABA release from interneurons via the activation of group I mGluRs.

Key words: IPSP; GABA; retrograde signal; voltage clamp; mGluR; synaptic inhibition

decrease cAMP production (Conn et al., 1994), which can reduce GABA release (Capogna et al., 1995). Glitsch et al. (1996) found that in cerebellum forskolin, an activator of adenylate cyclase, also reduced DSI, which was consistent with their hypothesis.

Despite many similarities, hippocampal DSI and cerebellar DSI differ in some ways (Alger and Pitler, 1995). For example, whereas cerebellar DSI reduces TTX-insensitive mIPSC frequency, in CA1 pyramidal cells mIPSCs are unaffected by DSI. That and other data have suggested that there are two mechanisms for DSI expression in cerebellum, but only one is significantly present in CA1. In view of these differences it was of particular interest to test the hypothesis that the retrograde process in hippocampus might be mediated by glutamate acting on presynaptic group II mGluRs.

We made whole-cell voltage-clamp recordings of monosynaptic, evoked IPSCs in CA1 pyramidal cells in the rat hippocampal slice and used a battery of mGluR agonists and antagonists to test the mGluR hypothesis of DSI. Antagonism of DSI by $(S)$-MCPG and similarities between the actions of mGluR agonists and DSI support the hypothesis that glutamate, or a glutamate-like compound, could be the retrograde messenger of DSI in CA1 pyramidal cells, although the mechanism does not involve the group II mGluR subtype. This hypothesis has interesting implications for understanding both the mechanism by which the DSI process mediates DSI and the apparent differences between hippocampal and cerebellar DSI.

Some of the data in this report have appeared in abstract form (Alger et al., 1997).

\section{MATERIALS AND METHODS}

Preparation of hippocampal slices. Adult male Sprague Dawley rats (125$250 \mathrm{gm}$ ) were anesthetized deeply with halothane and decapitated; the brain was removed, and the hippocampi were dissected free. The hippocampi were mounted on an agar block in a slicing chamber containing ice-cold saline. Transverse slices $(400 \mu \mathrm{m})$ were cut with a Vibratome (Technical Products International, Chicago, IL) and allowed to recover in a holding chamber at the interface of a physiological saline and 
humidified $95 \% \mathrm{O}_{2} / 5 \% \mathrm{CO}_{2}$ atmosphere at room temperature. After a minimum $1 \mathrm{hr}$ incubation, a single slice was transferred to a submersiontype recording chamber (Nicoll and Alger, 1981), where it was perfused with oxygenated saline $\left(29-31^{\circ} \mathrm{C}\right)$ at a flow rate of $0.5-1 \mathrm{ml} / \mathrm{min}$.

Solutions. Patch electrodes with resistances 3-6 M $\Omega$ usually were filled with (in mM): $\mathrm{CsCH}_{3} \mathrm{SO}_{3} 100, \mathrm{CsCl} 50$ or 60, BAPTA 2, $\mathrm{CaCl}_{2} 0.2$, $\mathrm{MgCl}_{2} 1$, MgATP 2 or 4, HEPES 10, Tris-GTP 0.3 , and 2-(triethylamino)- $N$-(2,6-dimethylphenyl) acetamide (QX-314) $5, \mathrm{pH}$ adjusted to 7.3 with $\mathrm{KOH}$, osmolarity $310-320 \mathrm{mOsm}$. In some experiments $145 \mathrm{~mm} \mathrm{KCl}$ was used in place of the Cs salts; other constituents were the same. The results using these two electrode solutions did not differ. Physiological saline contained (in mM): $\mathrm{NaCl} 120, \mathrm{KCl} 3.5, \mathrm{NaH}_{2} \mathrm{PO}_{4}$ $1.25, \mathrm{NaHCO}_{3} 25, \mathrm{CaCl}_{2} 2, \mathrm{MgSO}_{4} 2$, and glucose 10 , equilibrated with a $95 \% \quad \mathrm{O}_{2} / 5 \% \quad \mathrm{CO}_{2}$ mixture, $\mathrm{pH}$ 7.3. 6-Cyano-7-nitroquinoxaline-2,3dione (CNQX; $20 \mu \mathrm{M}$ ) and D,L-2-amino-5-phosphonovaleric acid (APV; $50 \mu \mathrm{M}$ ) were used in all experiments in the extracellular saline to block ionotropic glutamate responses. TTX, $0.5 \mu \mathrm{M}$, was present in the bath solution for experiments on miniature IPSCs (mIPSCs) to block action potential-dependent transmitter release. Recording of mIPSCs was initiated only after high-intensity stimulation elicited no IPSC.

The metabotropic glutamate receptor (mGluR) agonists L-quisqualic acid (Quis), ( $S$ )-3,5-dihydroxyphenylglycine (DHPG), (1S,3R)-1aminocyclopentane-1,3-dicarboxylic acid [ $(1 S, 3 R)$-ACPD], $\left(2 S, 2^{\prime} R, 3^{\prime} R\right)$ 2-(2',3'-dicarboxycyclopropyl)glycine (DCG-IV), $\left(2 S, 1^{\prime} S, 2^{\prime} S\right)-2$-(carboxycyclopropyl)glycine (L-CCG-I), L(+)-2-amino-4-phosphonobutyric acid (L-AP4), as well as the mGluR antagonists L(+)-2-amino-3phosphonopropionic acid (L-AP3), ( $S$ )-4-carboxyphenylglycine (4CPG), $(R S)$ - $\alpha$-methylserine- $O$-phosphate (MSOP), ( $S)$-2-amino-2-methyl-4phosphonobutanoic acid (M-AP4), and $(S)$ - $\alpha$-methyl-4-carboxyphenylglycine $[(S)-\mathrm{MCPG}]$ were purchased from Tocris Cookson (Bristol, UK). CNQX was acquired from Research Biochemicals (Natick, MA), BAPTA from Molecular Probes (Eugene, OR), and TTX from Calbiochem (La Jolla, CA). QX-314 was generously donated by Astra (Sodertalje, Sweden) or was purchased from Alomone Labs (Jerusalem, Israel). All other drugs and chemicals were from Sigma (St. Louis, MO). Drugs were either iontophoretically- or bath-applied. All agonists and antagonists of mGluRs were prepared as concentrated stock solutions: $(1 S, 3 R)$ ACPD, L-CCG-I, quisqualate, L-AP4, and DHPG were dissolved at $1000 \times$ final concentration in 1 equivalent (eq) of $\mathrm{NaOH}$ (except for DHPG, which was prepared in distilled water); L-AP3 and (S)-MCPG were solubilized at $100 \times$ final concentration in 1 eq or 1.1 eq of $\mathrm{NaOH}$. All other bath-applied drugs were prepared as 1:1000 concentrated stock solutions.

Electrophysiology and data analysis. Tight-seal whole-cell recordings were obtained from CA1 pyramidal cells via the "blind" technique (Blanton et al., 1989). The cells were voltage-clamped at $-70 \mathrm{mV}$ immediately after break-in, using either an Axopatch 200A or Axoclamp 2B amplifier (Axon Instruments, Foster City, CA). Acceptable cells had resting potentials more than or equal to $-55 \mathrm{mV}$ and input resistances $>40 \mathrm{M} \Omega$. Series resistance and input resistance were monitored continuously (every 2, 16, or $120 \mathrm{sec}$ ) by observing changes in the amplitude characteristics of the capacitive current elicited by a $5 \mathrm{mV}, 50 \mathrm{msec}$ hyperpolarizing rectangular voltage step. Experiments with unstable series resistances or series resistances $>30 \mathrm{M} \Omega$ were discarded. Series resistance compensation was between 50 and $70 \%$. Liquid junction potentials were small and were not corrected for. Evoked inhibitory postsynaptic currents were recorded by stimulating either stratum oriens or stratum radiatum at 0.33 or $0.5 \mathrm{~Hz}$ with a bipolar concentric stimulating electrode (Rhodes Electronics). Extracellular field EPSPs were recorded with electrodes (resistances 2-5 M $\Omega$ ) filled with buffered salt solution having the same composition as the physiological saline. Mossyfiber field EPSPs recorded in s. lucidum were evoked by a stimulating electrode placed in s. granulosum of the dentate gyrus. CA1 field EPSPs were recorded in s. radiatum. To record CA1 field EPSPs, we removed the CA3 region and placed a stimulating electrode in s. radiatum near the cut edge. Field EPSPs were evoked at $0.1 \mathrm{~Hz}$. Signals were filtered at 2 $\mathrm{kHz}$ with an eight-pole Bessel filter (Frequency Devices, Haverhill, MA), digitized at $10 \mathrm{kHz}$ with a DigiData 1200 interface board (Axon Instruments), and analyzed with pCLAMP 6 software (Axon Instruments). Data also were stored on VHS videotape after being acquired at $22 \mathrm{kHz}$ with a 14-bit PCM digitizer (Neuro-Corder DR-484, Neuro Data Instruments).

Iontophoresis of $(1 S, 3 R)$-ACPD was performed in some experiments. $(1 S, 3 R)$-ACPD was dissolved at $25 \mathrm{~mm}$ in 1 eq of $\mathrm{NaOH}$ and was present at full strength in the iontophoretic pipettes. The drug was ejected from glass pipettes with resistances of 1-2 $\mathrm{M} \Omega$ positioned in the vicinity of the recording patch electrode. Iontophoretic currents of -155 to $-600 \mathrm{nA}$ lasting from 2 to $4 \mathrm{sec}$ were used.

Positive voltage step commands to $\sim 0 \mathrm{mV}$ for a duration of $1-2 \mathrm{sec}$ were used to elicit DSI every $90-120 \mathrm{sec}$. With this protocol an unclamped $\mathrm{Ca}^{2+}$ spike current and $\mathrm{K}^{+}$currents were present in the current trace. DSI was expressed as the percent reduction of the control response by calculating the mean amplitude of 7 or 10 IPSCs in the control (pre-DSI) period and the mean amplitude of the same number of IPSCs after the DSI step. Because DSI often is not maximal immediately after the step and takes $\sim 1-3 \mathrm{sec}$ to develop (Pitler and Alger, 1994; Alger et al., 1996), we typically omitted the first two IPSCs during the DSI period from the calculations.

To quantify drug effects on DSI, we compared the mean of two to four complete DSI trials in control (predrug period) with the mean of the equal number of DSI trials at the time of maximum drug effect. The percent reduction of IPSC amplitude by the given drug was calculated by comparing the mean amplitudes in the pre-DSI period in control and during the drug effect. The percent reduction of IPSCs by iontophoretic $(1 S, 3 R)$-ACPD application was computed in the same manner, comparing the mean amplitude of 7-10 IPSCs before and after drug ejection at the time of maximum effect. Unless otherwise stated, a Student's paired $t$ test was used to determine statistical significance of effects $(p<0.05)$, and all data are reported as the mean \pm SEM.

The significance of $(1 S, 3 R)$-ACPD effects on mIPSCs was assessed by Kolmogorov-Smirnov (K-S) statistics with a significance level of $p<$ 0.005 . Cumulative frequency amplitude distributions of TTX-insensitive mIPSCs were obtained over $1 \mathrm{~min}$ in the control period and during the subsequent application of $(1 S, 3 R)$-ACPD. Averaged cumulative frequency amplitude distributions were constructed by normalizing individual distributions to the median amplitude of the corresponding control distributions. Data from individual cells were averaged by calculating the normalized amplitudes at fixed cumulative frequency intervals.

\section{RESULTS}

\section{$(1 S, 3 R)-A C P D$ reduces IPSCs and DSI}

The results presented in this report are based on whole-cell voltage-clamp experiments done on 134 cells recorded in the CA1 pyramidal layer of the rat hippocampal slice. The ionotropic glutamate receptor antagonists CNQX $(20 \mu \mathrm{M})$ and APV $(50 \mu \mathrm{M})$ were present in all experiments except for those on field potential EPSPs.

Confirming previous reports (Desai et al., 1994; Jouvenceau et al., 1995), we found that the mGluR agonist (1S,3R)-ACPD bath-applied at $50(n=15)$ or $100 \mu \mathrm{M}(n=4)$ substantially suppressed the evoked monosynaptic GABA $_{\mathrm{A}}$ R-mediated IPSC $(55.6 \pm 5.3 \%$; Fig. $1 A, D, n=19)$. In 18 of these cells DSI was present; the mean suppression of the IPSC during DSI was $51 \pm$ $3.4 \%$ of the control amplitude. $(1 S, 3 R)$-ACPD reduced the IPSC by $53.9 \pm 5.3 \%$ and reduced DSI in these cells to $17 \pm 4 \%$ suppression. In 10 cells we tested for recovery and found that DSI recovered after $50 \mu \mathrm{M}(1 S, 3 R)$-ACPD was washed out (control DSI, $54 \pm 4.3 \%$; wash DSI, $50 \pm 5.6 \%$ ) (Fig. $1 C$ ).

The block of DSI induced by $(1 S, 3 R)$-ACPD could not be explained simply by the reduction in IPSC size because when, still in $(1 S, 3 R)-A C P D$, the stimulus intensity was increased to produce an IPSC similar to the control IPSC, DSI did not increase (Fig. $1 B, C)$. DSI recovered when $(1 S, 3 R)$-ACPD was washed from the bath, however $(n=5)$. Thus it appears that activation of mGluRs mimics and occludes hippocampal CA1 DSI as it does cerebellar DSI (Glitsch et al., 1996).

Both DSI and $(1 S, 3 R)$-ACPD decrease the frequency of TTXinsensitive mIPSCs in cerebellum (Llano et al., 1991; Llano and Marty, 1995). In hippocampus, DSI does not block mIPSCs (Pitler and Alger, 1994; Alger et al., 1996). We recorded mIPSCs during 1 min intervals from six cells in TTX and then applied $(1 S, 3 R)$-ACPD $(50 \mu \mathrm{M})$ and compared the mIPSCs in $(1 S, 3 R)$ - 

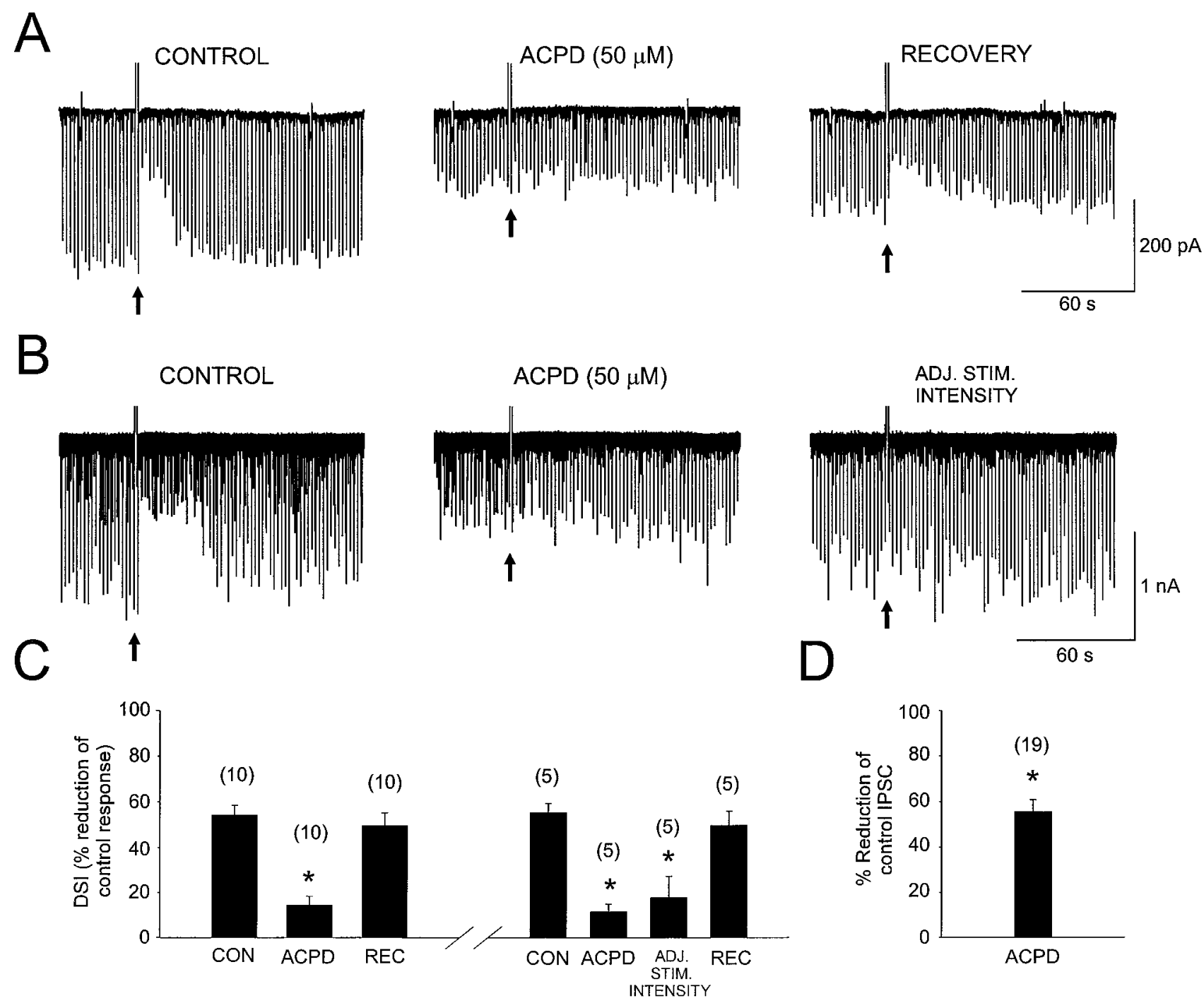

Figure 1. Activation of mGluRs by $(1 S, 3 R)$-ACPD reduces DSI of evoked monosynaptic $\mathrm{GABA}_{\mathrm{A}} \mathrm{R}$-mediated IPSCs recorded from hippocampal CA1 pyramidal cells. $A$, Illustrated is a control DSI trial on a series of evoked IPSCs (these inward currents are shown as downward deflections). DSI was elicited by a depolarizing voltage step [depolarizing voltage steps (see Materials and Methods) are indicated by filled arrows in all figures] and is represented by the transient reduction of the IPSCs. The center trace is from a DSI trial on the same cell during the fifth minute of bath application of $(1 S, 3 R)$-ACPD. The IPSCs are reduced in amplitude, and DSI is occluded. The right trace is from a DSI trial recorded 22 min after washout of $(1 S, 3 R)$-ACPD. B, Recorded from another cell, the first current trace (left) shows the control DSI trial. The center trace shows the effects of $(1 S, 3 R)$-ACPD (recorded during the fourth minute of bath application). The right trace is from a DSI trial after the stimulation intensity had been increased (ADJ. STIM. INTENSITY) to evoke IPSCs comparable in amplitude to those recorded in control. Note that DSI remains reduced after this manipulation. $C$, Combined data summarizing the action of $(1 S, 3 R)$-ACPD on DSI from 10 experiments as in $A$. In the same graph (separated by the break in the ordinate) are data recorded from a different set of cells summarizing experiments performed as in $B$. Data in control and recovery are labeled $C O N$ and $R E C$, respectively. $D$, Summarized is the suppression of the IPSC amplitude produced by bath-applied ( $1 S, 3 R)$-ACPD. Data in graphs $C$ and $D$ were obtained from the number of cells shown in parentheses above the bars. Asterisks in the figures indicate significant differences from control values (Student's paired $t$ test; $p<0.05$ ). In this and other figures stimulus artifacts were blanked for clarity in the display.

ACPD with those in control. There was no change in mIPSC frequency (control, $4.8 \pm 1 \mathrm{~Hz} ;(1 S, 3 R)$-ACPD + TTX, $5.29 \pm 1$ $\mathrm{Hz}$ ) or amplitude (Fig. 2). That bath-applied (1S,3R)-ACPD was active in these cells was evident by the small inward currents, 30-60 pA (see, for example, Fig. 2), that it induced. Note that in experiments performed with Cs-based electrode filling solutions and iontophoretic application of $(1 S, 3 R)$-ACPD, direct postsynaptic membrane effects, such as these inward currents, were undetectably small (see Figs. 4,6,7) and cannot account for the effects we report.

\section{Evidence against group II or group III mGluR involvement in DSI}

$(1 S, 3 R)-A C P D$ is an agonist at group I and group II mGluRs; hence it was not clear which class was responsible for IPSC suppression in CA1. In cerebellum the highly selective group II agonist DCG-IV $(0.5-5 \mu \mathrm{M})$ potently blocked IPSCs and occluded DSI (Glitsch et al., 1996). In CA1 we found that bath application of $10 \mu \mathrm{M}$ DCG-IV to five pyramidal cells, in which robust DSI of evoked IPSCs was present, affected neither the IPSC amplitudes nor DSI (control DSI, $43 \pm 4.7 \%$; DCG-IV 

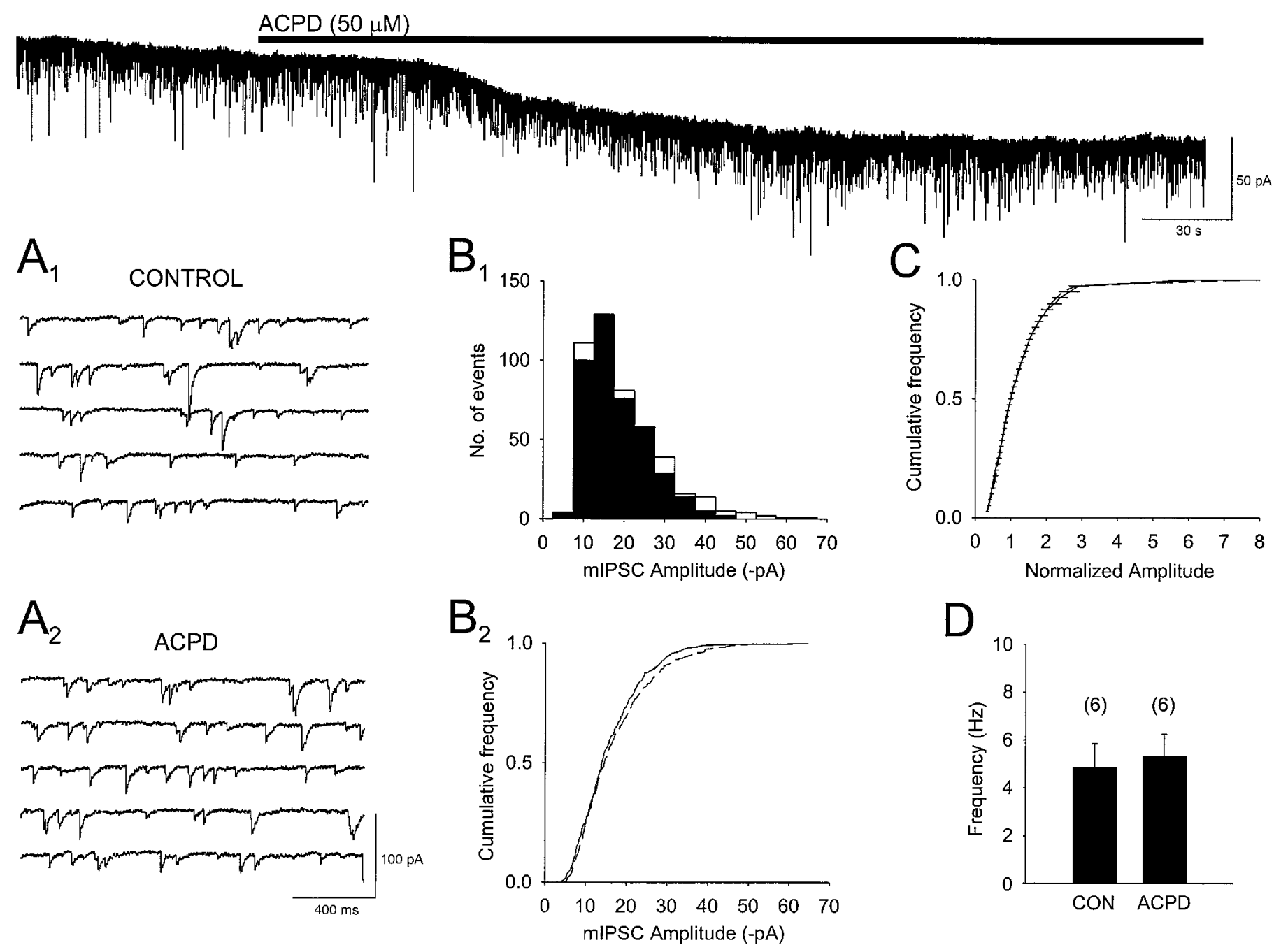

Figure 2. (1S,3R)-ACPD does not affect the amplitude or frequency of TTX-insensitive mIPSCs. The top trace illustrates the actions of bath-applied $(1 S, 3 R)$-ACPD (duration of application is indicated by the solid bar) on a continuous record of spontaneous mIPSCs in the presence of $0.5 \mu \mathrm{M}$ TTX. $(1 S, 3 R)$-ACPD produced an inward current of $\sim 30 \mathrm{pA} . A_{1}$, Traces of mIPSCs on an expanded time scale recorded during the control period before the application of $(1 S, 3 R)$-ACPD. $A_{2}$, Shown are mIPSCs during the sixth minute of $(1 S, 3 R)$-ACPD perfusion. $B_{1}$, Corresponding amplitude histograms of the mIPSCs before ( filled bars) and in the presence of $(1 S, 3 R)$-ACPD (open bars). Measurements were taken for 1 min in each condition. $B_{2}$, Cumulative amplitude distributions obtained in $B_{1}$ for mIPSCs recorded in control (solid line) and in the presence of (1S,3R)-ACPD (dashed line) for the experiment shown in $A$. $C$, Averaged cumulative amplitude distributions of mIPSCs obtained from six cells in control and then in (1S,3R)-ACPD. $D$, Bar graph shows mean mIPSC frequencies in control and in the presence of $(1 S, 3 R)$-ACPD $(n=6)$. $(1 S, 3 R)$-ACPD had no significant effect on the frequency of mIPSCs. Individual amplitude distributions of events in $B_{2}$ and $C$ in control and in ( $\left.1 S, 3 R\right)$-ACPD are not statistically significant, as determined by Kolmogorov-Smirnov tests $(p<0.005)$.

DSI, $46 \pm 6.1 \%)\left(\right.$ Fig. $\left.3 A_{1}\right)$. We confirmed (Kamiya et al., 1996) that $1 \mu \mathrm{M}$ DCG-IV was effective in CA3, however, reducing evoked field potentials by $79 \pm 4.2 \%(n=7)$ (Fig. $\left.3 A_{2}\right)$, and in a separate study (Morishita and Alger, 1997b) we verified that 10 $\mu \mathrm{M}$ DCG-IV reduces CA3 IPSCs (see Poncer et al., 1995). The $\mathrm{EC}_{50}$ of L-CCG-I for phosphoinositide (PI) hydrolysis caused by expressed mGluR1 is $\sim 50 \mu \mathrm{M}$ (Suzdak et al., 1994). The $\mathrm{EC}_{50}$ of L-CCG-I for the inhibition of forskolin-stimulated CAMP production by expressed mGluR4 is $\sim 50 \mu \mathrm{M}$, whereas its $\mathrm{EC}_{50}$ in the same assay when mediated by expressed mGluR2 is $0.3 \mu \mathrm{M}$. Thus at low concentrations L-CCG-I is relatively selective for mGluR2. We found that L-CCG-I, at $3 \mu \mathrm{M}$, had no effect on either evoked IPSCs or DSI $(n=6$; Fig. $3 B$ ). In one cell we then increased the dose of L-CCG-I to $100 \mu \mathrm{M}$ and found that both IPSCs and DSI were reduced dramatically. The lack of effect of group II mGluR agonists on IPSCs means that these receptors probably are not involved in DSI.

The mGluR agonist, L-AP4, is selective for group III mGluRs (mGluR4, mGluR6, mGluR7, and mGluR8). Although mGluR6 does not appear to be present in hippocampus and the levels of mGluR4 and mGluR8 are very low in CA1 (Testa et al., 1994; Shigemoto et al., 1997), mGluR7 is present (Okamoto et al., 1994; Saugstad et al., 1994; Shigemoto et al., 1997). L-AP4 bath-applied at $200 \mu \mathrm{M}$ to six cells reduced the IPSCs by a mean of $39 \pm 4.9 \%$. Gereau and Conn (1995b) found that L-AP4 did not block IPSCs when glutamatergic transmission was blocked by APV and CNQX, implying that L-AP4 acted at another site, probably the excitatory nerve terminals onto the interneurons. Our experiments were done in CNQX and APV; hence this explanation could not account for our data. Nevertheless, glutamate still was 
$A_{1}$

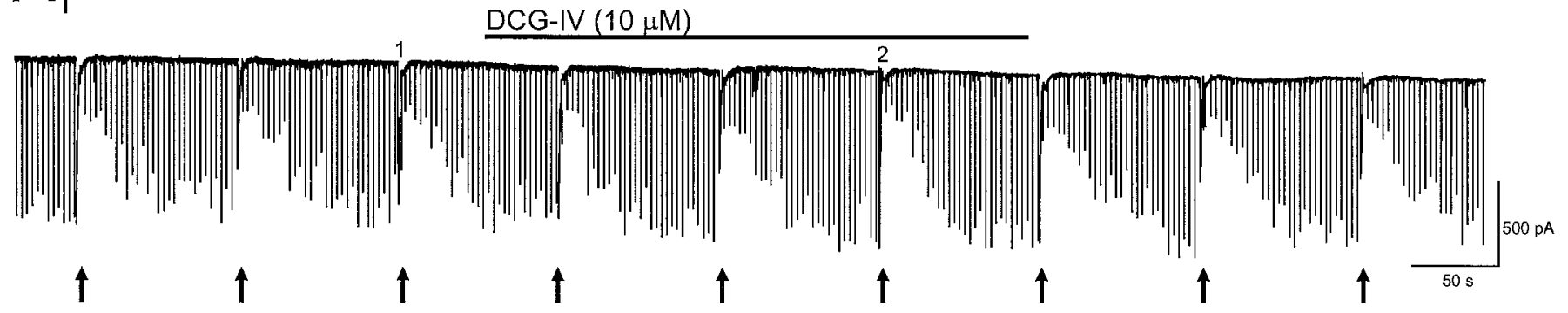

\section{CONTROL DCG-IV}
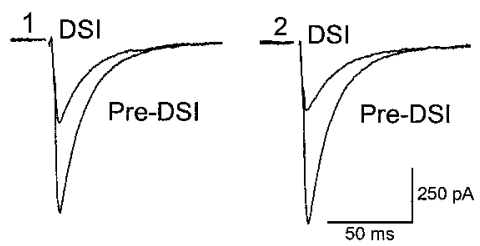

$250 \mathrm{pA}$

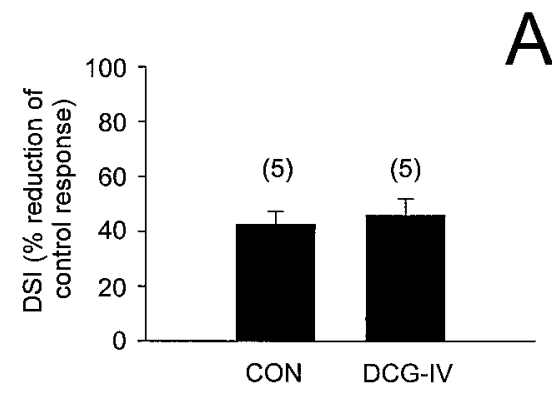

$\mathrm{A}_{2}$

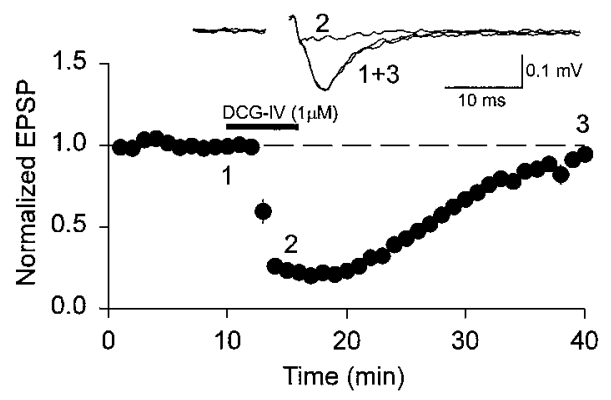

B

CONTROL

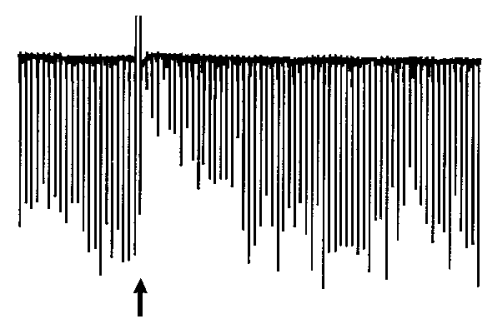

L-CCG-1 (3 $\mu \mathrm{M})$

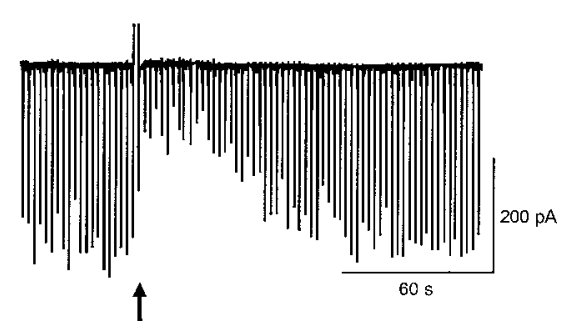

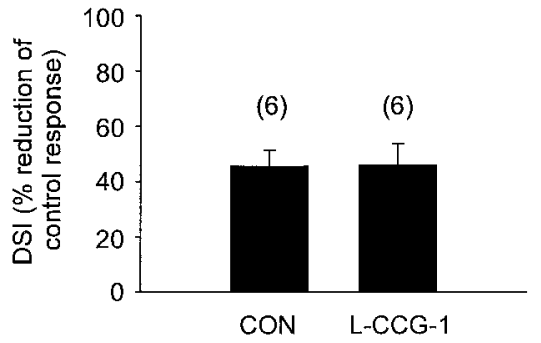

Figure 3. Group II mGluRs are not involved in CA1 DSI. $A_{1}$, Continuous trace of IPSCs showing several DSI trials. Below the trace are averages of five consecutive IPSCs recorded at the indicated time points before (Pre-DSI) and after the voltage step (DSI) in control and in the presence of the specific group II mGluR agonist, $D C G-I V$, applied at $10 \mu \mathrm{M}$ (duration of application is indicated by the solid bar above the continuous trace). Next to the averaged traces is a bar graph summarizing the data from five cells. DSI is not significantly altered by DCG-IV. $A_{2}$, The graph shows that $1 \mu \mathrm{M}$ DCG-IV suppressed mossy fiber-CA3 field EPSPs $(n=7$ slices $)$ and hence is active under our conditions. EPSPs above the graph are averages of six consecutive responses recorded at the indicated time points from one slice. B, The first trace (left) shows a control DSI trial, and the trial to the right is from the same cell during the eighth minute of application of the group II mGluR agonist, L-CCG-I. Results from six such experiments are shown in the bar graph located to the right of the current traces. L-CCG-I had no effect on DSI.

released in the presence of CNQX and APV, so we considered whether or not synaptically released glutamate could affect IPSCs by activation of mGluRs on interneurons. Adenosine inhibits glutamate release without affecting GABA release (Lambert and Teyler, 1991). We found that $50 \mu \mathrm{M}$ adenosine did not alter the ability of L-AP4 to reduce IPSCs $(47 \pm 14.3 \%$ reduction in control vs $46 \pm 15.9 \%$ reduction in adenosine; $n=4$ ), a result that is explained most easily as a direct inhibitory effect of group III mGluRs on GABAergic interneurons, rather than as an indirect effect.

Despite its suppression of monosynaptic IPSCs, L-AP4 did not reduce DSI significantly (control DSI, $42 \pm 4.7 \%$; L-AP4 DSI, $37 \pm 4.0 \%$ ) (Fig. $4 A_{1}, A_{2}, p=0.2 ; n=11$ ), even when stimulus intensity was increased to restore IPSC amplitudes to control levels (Fig. 4A). Moreover, neither the group III mGluR antagonist MSOP, $200 \mu \mathrm{M}$ (control DSI, $48 \pm 7.8 \%$; MSOP DSI, $50 \pm 7.8 \% ; n=6$ ), nor the antagonist M-AP4, 2.5 mM, affected DSI (Fig. $4 C, n=4$ ). As also shown in Figure $4 C$,
M-AP4 had no effect on iontophoretically applied $(1 S, 3 R)$ ACPD-induced IPSC suppression, although M-AP4, $1 \mathrm{~mm}$, completely and reversibly blocked the effects of $50 \mu \mathrm{M} \mathrm{L}-\mathrm{AP} 4$ on the CA1 field EPSP (Fig. $4 B$ ). These data argue against a role for group III mGluRs in DSI.

Group II and group III mGluRs produce their effects mainly by inhibiting adenylate cyclase (Conn et al., 1994). We found (data not shown) that bath application of $50 \mu \mathrm{M}$ forskolin enhanced monosynaptic IPSC amplitude (by $60 \pm 14 \%$; $n=8$ ), as previously reported (Capogna et al., 1995). Forskolin had no effect on DSI, however, which in these cells amounted to a depression of $54 \pm 3.6 \%$ in control and $45 \pm 5.9 \%$ in forskolin $(p=0.09)$. Because forskolin did occlude DSI and the effects of the group II agonists in cerebellum (Glitsch et al., 1996), our results are consistent with a lack of participation of group II or group III mGluRs in hippocampal CA1 DSI, assuming that the depression of synaptic transmission mediated by these receptors is caused by cAMP reduction. 


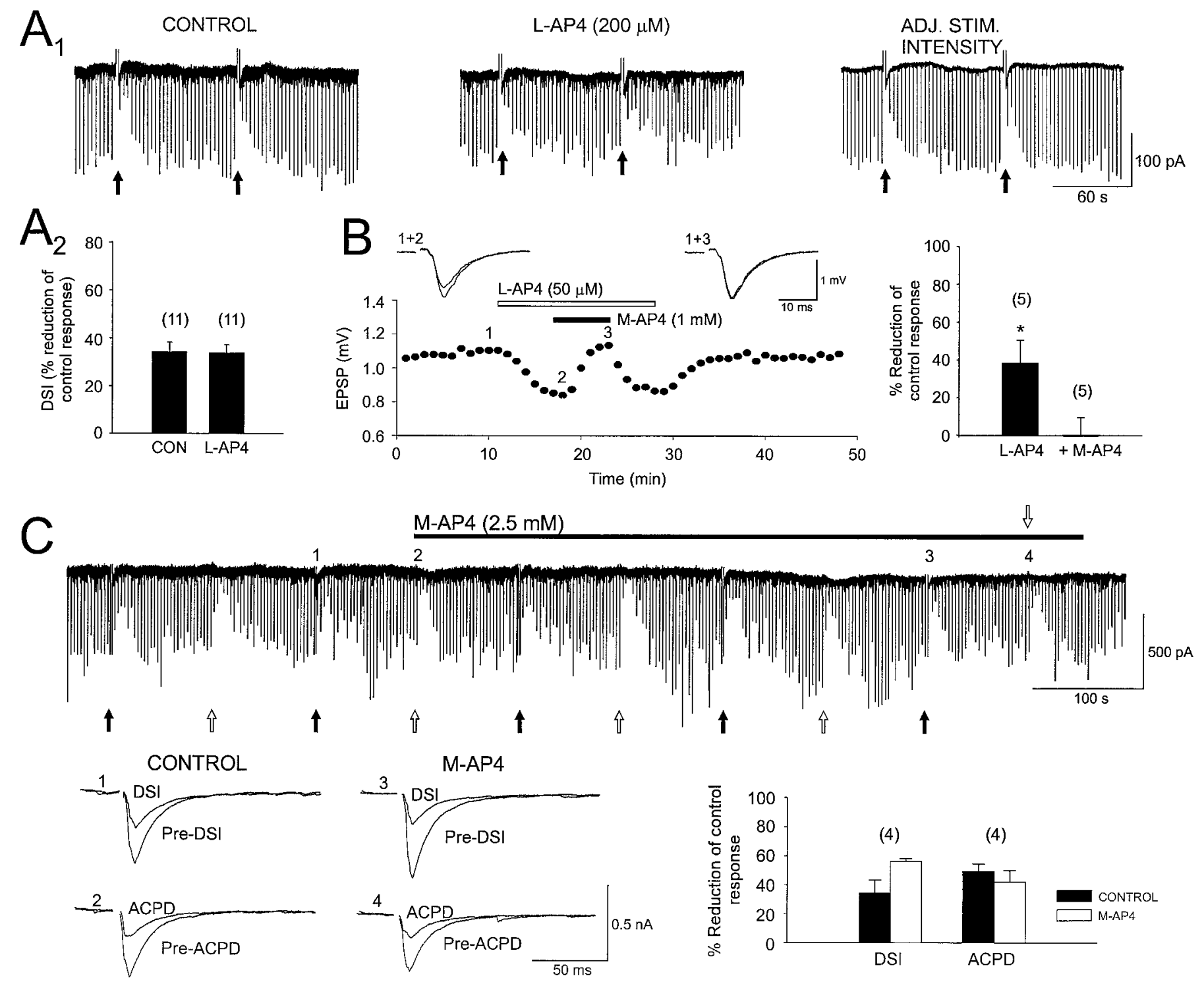

Figure 4. Group III mGluRs are not involved in CA1 DSI. $A_{l}$, The first current trace (left) illustrates two control DSI trials. The center trace shows two DSI trials recorded from the same cell during the fifth minute of application of the group III mGluR agonist, L-AP4. The trials in the right trace also were recorded in L-AP4 after the stimulation intensity had been increased (ADJ. STIM. INTENSITY) to elicit IPSCs comparable in amplitude to those recorded in control. $A_{2}$, The bar graph summarizes results from 11 experiments similar to those in $A_{1}$. DSI was not affected significantly by L-AP4. $B$, An experiment showing that the suppression of CA1 field EPSPs by L-AP4 can be blocked by M-AP4, under our conditions, and hence that M-AP4 is an effective group III antagonist. EPSPs displayed above the graph are averages of six consecutive responses recorded at the indicated time points from one slice. Results from five experiments are summarized in the bar graph to the right. The continuous trace in $C$ shows that M-AP4 (the duration of application is indicated by the solid bar) blocks neither DSI ( filled arrows) nor the suppression of IPSCs induced by iontophoresis of (1S,3R)-ACPD (open arrows). Below the trace are IPSCs recorded at the indicated time points before (Pre-DSI) and during DSI $(D S I)$ as well as before (Pre-ACPD) and after $(A C P D)$ iontophoresis of $(1 S, 3 R)$-ACPD. Individual IPSCs are the averages of five consecutive responses. The bar graph to the right summarizes results from four experiments. $(1 S, 3 R)$-ACPD was iontophoresed by a $-155 \mathrm{nA}, 2$ sec current. Asterisks denote significant differences from control values.

\section{Group I mGluR agonists mimic and occlude DSI}

The efficacy of $(1 S, 3 R)$-ACPD and a high concentration of L-CCG-I in reducing IPSCs and DSI suggested that group I mGluRs (mGluR1 and mGluR5) could be responsible. At low concentrations $(\leq 10 \mu \mathrm{M})$ quisqualate is fairly selective for group I (Suzdak et al., 1994). We tested the effects of quisqualate at 2 $(n=3), 5(n=3)$ and $10 \mu \mathrm{M}(n=2)$ and found that each was highly effective in reducing IPSC amplitudes (pooling results from these experiments gave a mean suppression of IPSC amplitudes of $70 \pm 5.6 \%$ from control) (Fig. $5 D, n=8$ ) and DSI from $48 \pm 3.6 \%$ to $19 \pm 3.7 \%$ (Fig. $5 A, C, n=7$ ). DHPG, $100 \mu \mathrm{M}$, is quite specific for group I mGluRs (Ito et al., 1992; Schoepp, 1994; Brabet et al., 1995; Gereau and Conn, 1995b). DHPG reduced IPSCs (to $52.9 \pm 4.4 \%$ of control, Fig. $5 D$ ) and DSI (from $51 \pm$ $5.3 \%$ in control to $17 \pm 4.2 \%$ in DHPG) (Fig. $5 B, C, n=6$ ). Thus the activation of group I mGluRs can mimic and occlude DSI.

\section{(S)-MCPG reduces (1S,3R)-ACPD-induced suppression of IPSCs and DSI}

The mGluR antagonist, L-AP3, blocks cerebellar DSI; however, when bath-applied at $1 \mathrm{~mm}, \mathrm{~L}-\mathrm{AP} 3$ had no consistent effect on CA1 IPSCs or DSI. Of four cells it had no apparent effect on DSI 
A
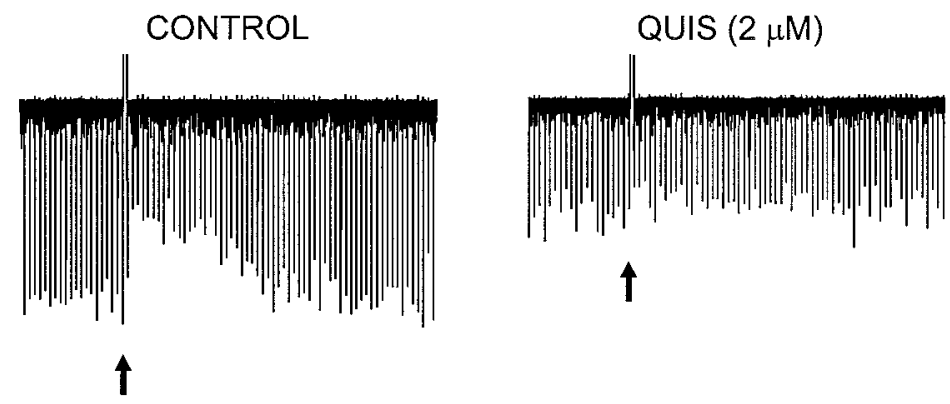

B

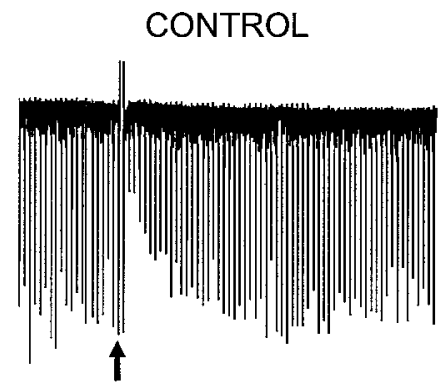

C

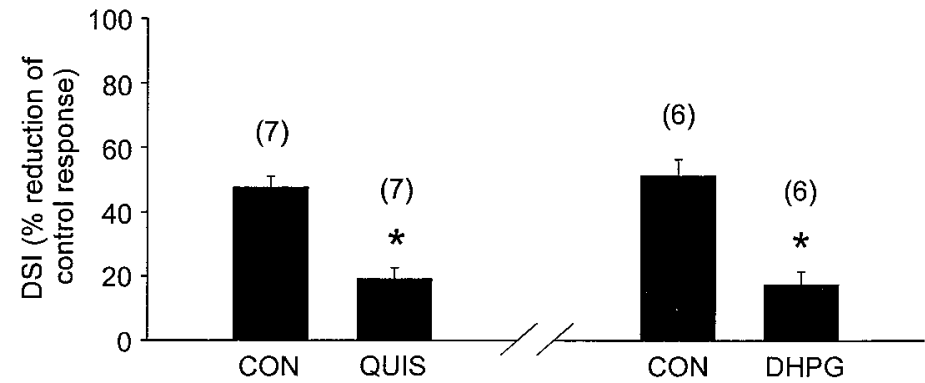

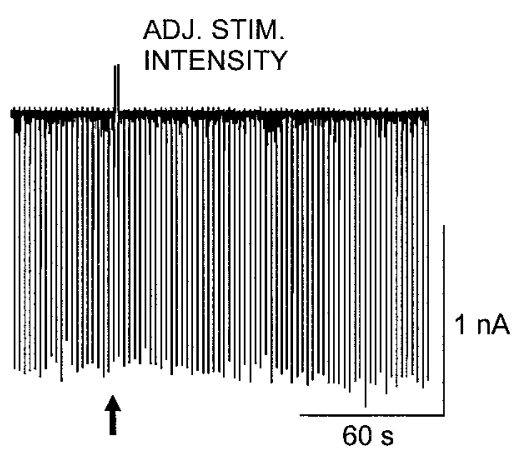
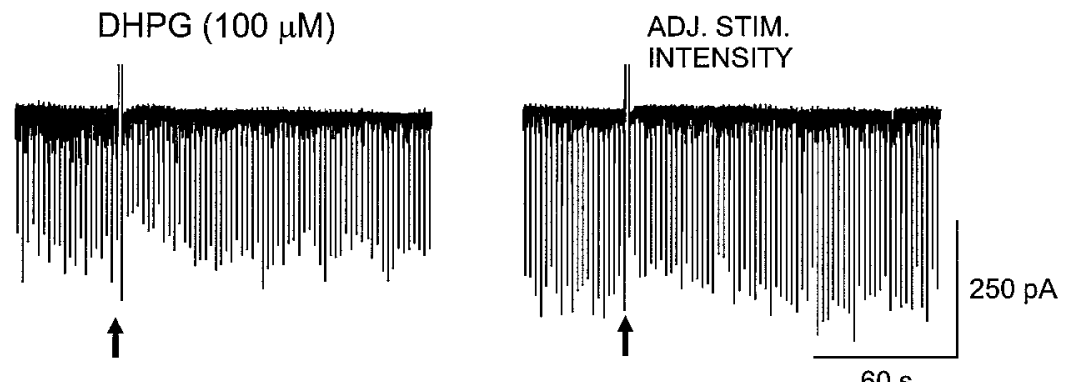

$60 \mathrm{~s}$

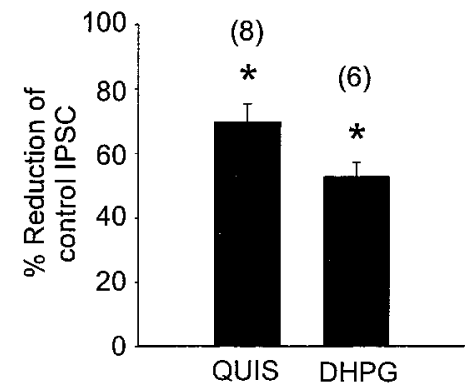

Figure 5. Group I mGluR agonists, L-quisqualate and DHPG, reduce the amplitude of evoked monosynaptic IPSCs and occlude DSI. $A$, The first trace (left) shows the DSI of IPSCs recorded in the control saline. The center trace shows IPSCs recorded during the 10th min of bath application of L-quisqualate $(Q U I S)$. The right trace shows a DSI trial still in L-quisqualate after the stimulation intensity had been increased (ADJ. STIM. INTENSITY) to elicit IPSCs comparable to those in the control condition. $B$, Illustrated are the effects of DHPG on IPSCs and DSI; trace sequences are as in $A$. Both L-quisqualate and DHPG suppressed IPSCs and occluded DSI, and the effects persisted even after the stimulation intensity had been increased. $C$, A graph summarizes the effects of quisqualate and DHPG on DSI. D, A graph shows the effect of these agonists on IPSC amplitudes. Asterisks indicate significant differences from control values.

in three, and in one cell both the IPSC and DSI were diminished. When tested on DSI and iontophoretic $(1 S, 3 R)$-ACPD-induced IPSC suppression in another group of cells, L-AP3 had no significant effect on either ( $n=3$; data not shown). Thus L-AP3 appeared to be an ineffective mGluR antagonist in CA1 in our hands.

We examined the effect of $(S)$-MCPG on (1S,3R)-ACPDinduced IPSC suppression and DSI by bath-applying it at concentrations from 0.5 to $5 \mathrm{~mm}$. ( $1 S, 3 R)$-ACPD was applied iontophoretically from a pipette containing $25 \mathrm{~mm}(1 S, 3 R)$-ACPD (see Materials and Methods). Evoked IPSCs were suppressed on alternate trials by DSI or by iontophoretic $(1 S, 3 R)$-ACPD. $(S)$ MCPG caused a dose-dependent reduction in DSI, decreasing it, for example, by $10 \pm 6.9 \%$ at $0.5 \mathrm{~mm}$ and by $57 \pm 1.3 \%$ at $5 \mathrm{~mm}$ (Fig. 6A). (S)-MCPG was more effective in blocking $(1 S, 3 R)$ ACPD suppression of IPSCs than DSI, causing reductions of $42 \pm 12.7 \%$ and $82 \pm 16.8 \%$ at 0.5 and $5 \mathrm{~mm}$, respectively, in the same cells. $(S)$-MCPG had no significant effect on IPSC ampli- tudes even at $5 \mathrm{~mm}$ (control IPSC, $-1269 \pm 172 \mathrm{pA} ;(S)$-MCPG IPSC, $-1039 \pm 138 \mathrm{pA} ; p=0.1 ; n=5)$. We also tested the antagonist 4-carboxyphenylglycine (4CPG) because this has been proposed to distinguish between mGluR1 and mGluR5 effects (Brabet et al., 1995). At $200 \mu \mathrm{M}\left(K_{\mathrm{B}}=14.9 \pm 7.7 \mu \mathrm{M}\right.$ for blocking mGluR1 effects in LLC-PK1 cells) (Brabet et al., 1995), 4CPG did not affect DSI (control DSI, $54 \pm 9.2 \%$; 4CPG DSI $62 \pm$ $7.4 \%$ ) (see Fig. $6 B$ ) and also did not affect (1S,3R)-ACPDinduced IPSC depression (control $(1 S, 3 R)$-ACPD, $35 \pm 8.3 \%$; $4 \mathrm{CPG}(1 S, 3 R)-\mathrm{ACPD}, 40 \pm 8.3 \%)$. These results suggest that mGluR5 rather than mGluR1 might be involved in IPSC suppression (see Discussion).

(1S,3R)-ACPD does not block DSI by reducing voltagedependent $\mathrm{Ca}^{2+}$ currents in postsynaptic CA1 pyramidal cells

Activation of mGluRs can cause a modest reduction of voltagedependent $\mathrm{Ca}^{2+}$ current (VDCC) in CA1 cells (10-30\%) (Lester 


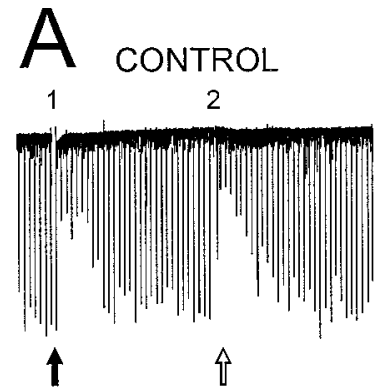

CONTROL
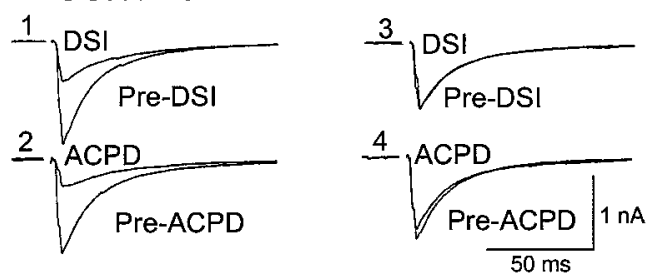
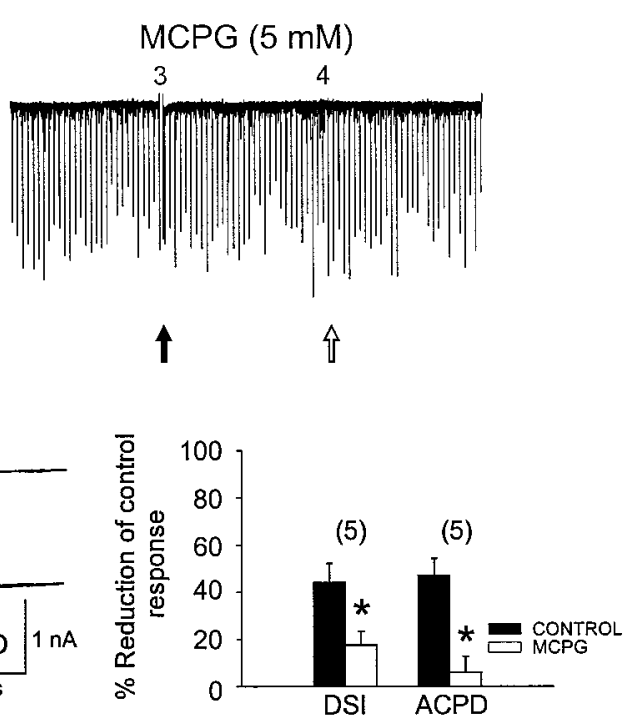
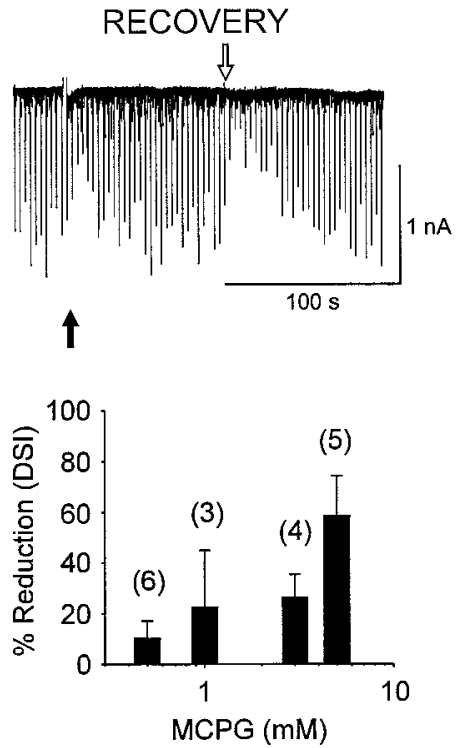
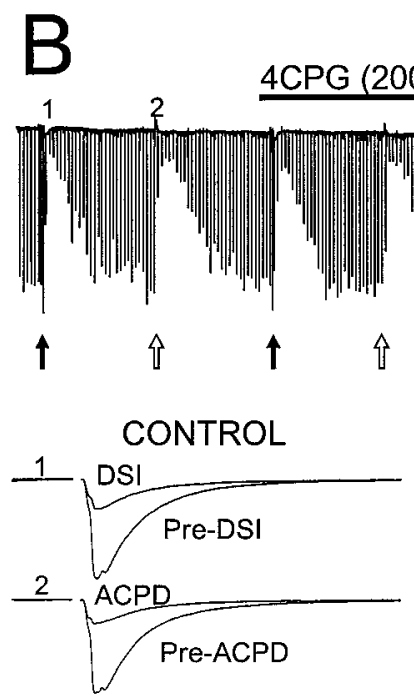

\section{$4 \mathrm{CPG}(200 \mu \mathrm{M})$}
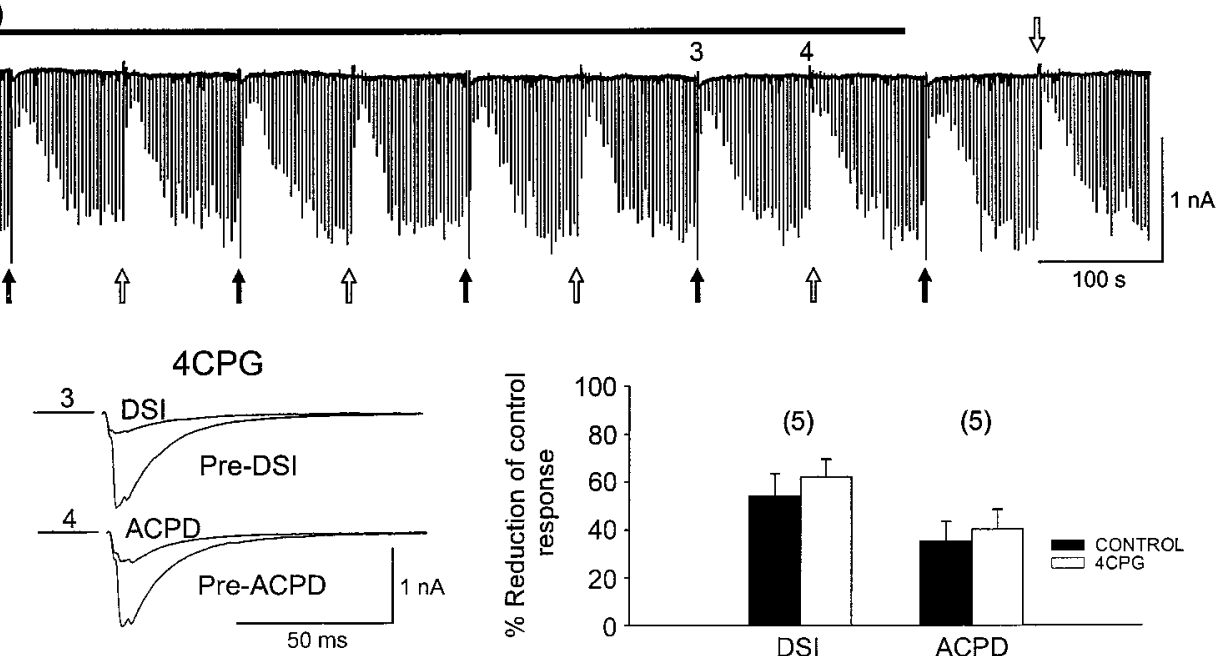

(5)

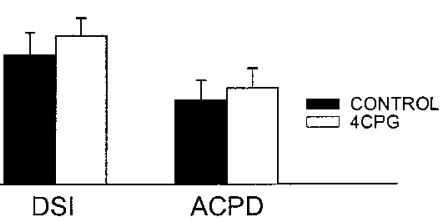

Figure 6. Selective block of DSI and the ( $1 S, 3 R)$-ACPD-induced suppression of IPSCs by $(S)$-MCPG, but not 4CPG. The current trace $(C O N T R O L)$ in $A$ illustrates the transient suppression of IPSCs during DSI ( filled arrows) and after iontophoresis of (1S,3R)-ACPD (open arrows). The trace to the right of control, $(M C P G)$ shows that both forms of IPSC suppression are antagonized during the 12th min of application of $(S)$-MCPG. The recovery trace shown to the far right was taken $40 \mathrm{~min}$ after we started to wash $(S)$-MCPG from the recording chamber. All current traces in $A$ were recorded from the same cell. To the left, in the bottom part of $A$, are IPSCs recorded at the indicated time points before (Pre-DSI) and during (DSI) as well as before $($ Pre- $A C P D)$ and after $(A C P D)$ iontophoretic application of $(1 S, 3 R)$-ACPD. The bar graph in the center summarizes the results from five cells. The bar graph to the extreme right shows the dose dependence of $(S)$-MCPG effects on DSI. $B$, Shown is a continuous record in which the evoked IPSCs were subjected to the same stimulating protocol as in A. Below the record are IPSCs recorded at the indicated time points. Note that 4CPG (duration of application is indicated by the solid bar) does not antagonize DSI or the (1S,3R)-ACPD-induced suppression of IPSCs. The bar graph illustrates the results from five cells. IPSCs in $A$ and $B$ are averaged traces from five consecutive responses. ( $1 S, 3 R)$-ACPD was iontophoresed by a $-155 \mathrm{nA}, 2$ sec current. Asterisks indicate significant differences from the control values.

and Jahr, 1990; Swartz and Bean, 1992; Trombley and Westbrook, 1992). Inasmuch as DSI induction depends on VDCCs in CA1 (Pitler and Alger, 1992; Lenz et al., 1997), it was conceivable that the reduction of DSI by mGluRs was dependent on this effect. However, (1) mGluR agonists had no consistent effect on clamp current during the DSI-inducing voltage steps, i.e., in an arbitrary group of 17 cells, the net current did not change in 10, decreased in the outward direction in four, and increased in the outward direction in three; (2) adenosine, which causes a greater reduction in VDCC in CA1 cells than does $(1 S, 3 R)$-ACPD (Kavalali et al., 1997), had no effect on DSI; and, finally, (3) reported mGluR effects on VDCCs are strictly dependent on the presence of GTP, or GTP $\gamma \mathrm{S}$, in the recording electrode. Omitting GTP from our pipette solution decreased the magnitude of G-protein-dependent responses (Pitler and Alger, 1994). Nevertheless, the $(1 S, 3 R)$ ACPD reduction of DSI in the absence of pipette GTP was not altered ( $n=4$; data not shown). Thus the effect of ( $1 S, 3 R)$-ACPD cannot be ascribed to any apparent action on postsynaptic VDCCs in CA1 pyramidal cells. In view of its strong suppressant effect on IPSCs, it seems most likely that $(1 S, 3 R)$-ACPD occludes DSI by reducing IPSCs by a presynaptic inhibition of GABA release, although there are other possibilities. 


\section{Other similarities between (1S,3R)-ACPD-induced IPSC suppression and DSI}

The previous data are consistent with a role for glutamate and mGluR in DSI. To test the hypothesis further, we examined other properties of mGluR-induced IPSC suppression. DSI can be reduced by 250-300 $\mu \mathrm{M}$ NEM (Morishita et al., 1997) and by bath application of the $\mathrm{K}^{+}$channel blocker 4-AP, $50 \mu \mathrm{M}$ (Alger et al., 1996). If an mGluR mediates the signal for DSI, then NEM and 4-AP should reduce the $(1 S, 3 R)$-ACPD-induced IPSC suppression. From the actions of mGluR1 agonists and the lack of effect of DCG-IV in CA1, we infer that the actions of $(1 S, 3 R)$-ACPD are on group I mGluRs in CA1. A limited-duration application (10 min) of NEM, $250 \mu \mathrm{M}$, blocked DSI at a time when IPSC amplitudes were increased over control values, as previously reported. NEM also consistently antagonized the effects of $(1 S, 3 R)$-ACPD on IPSCs (control IPSC suppression by $(1 S, 3 R)$ $\mathrm{ACPD}, 56 \pm 10.6 \%$; IPSC suppression by $(1 S, 3 R)-\mathrm{ACPD}$ in NEM, $6 \pm 3.3 \% ; n=6 ; p<0.01$ ) (Figure $7 A$ ). NEM effects were not reversible over the time course of our experiments (Morishita et al., 1997). The (1S,3R)-ACPD-induced suppression of IPSCs and DSI (Fig. $7 B_{1}$ ) was reversed by 4 -AP, and 4 -AP reduced DSI of evoked IPSCs (Fig. 7 $B_{2}$ ) (control DSI, $38 \pm 4 \%$; 4-AP DSI, $11 \pm 2.9 \% ; n=6$ ), as previously reported (Alger et al., 1996).

DSI does not affect the normal paired-pulse depression (PPD) of IPSCs that is present at a $200 \mathrm{msec}$ interstimulus interval (Alger et al., 1996; Morishita and Alger, 1997a). (1S,3R)-ACPD, $50 \mu \mathrm{M}$, reduced IPSCs by $56 \pm 4.7 \%$, and yet PPD, which was $77 \pm 2.8 \%$ in control, was $81 \pm 6.9 \%$ during $(1 S, 3 R)$-ACPD application (Fig. $8, p=0.5 ; n=7)$. Thus $(1 S, 3 R)$-ACPD, like DSI, reduced IPSC amplitude, but it did not alter PPD.

\section{DISCUSSION}

We examined the general hypothesis that glutamate, or an analog, might, via activation of an mGluR, act as a retrograde signal to suppress IPSCs in hippocampal DSI. Our data do not support the hypothesis that group II mGluRs mediate CA1 DSI (cf. Glitsch et al., 1996). This was not surprising, because there is little evidence that mGluR2 exists in CA1 (Shigemoto et al., 1997), and mGluR3 mRNA expression is low (Testa et al., 1994). We confirmed that, although active in CA3 (cf. Poncer et al., 1995; Morishita and Alger, 1997b), DCG-IV does not depress monosynaptic evoked IPSCs or mIPSCs in CA1 (Gereau and Conn, 1995a), and we found that neither DCG-IV nor low concentrations of L-CCG-I affected DSI. Forskolin, which blocks cerebellar DSI (Glitsch et al., 1996), had no effect on CA1 DSI.

Both group I and group III mGluR agonists suppressed IPSCs; however, only group I agonists occluded DSI, suggesting that only they mimic the DSI mechanism. MSOP and M-AP4, effective group III antagonists, did not block DSI. Moreover, because group III mGluRs reduce cAMP, as do group II receptors, the results of Glitsch et al. (1996) also suggest that forskolin should have reduced CA1 DSI if L-AP4-sensitive receptors had been involved.

Gereau and Conn (1995a) reported that L-AP4 blocked only polysynaptic, but not monosynaptic, IPSCs in CA1. In our hands L-AP4 consistently reduced IPSCs in CNQX and APV, even when adenosine was added to suppress glutamate release and further prevent the activation of polysynaptic IPSCs. The differences in results probably are explained by the activation of different interneurons in the two studies.

$(S)$-MCPG, a weak competitive mGluR antagonist, reduced DSI in a dose-dependent way. The efficacy of $(S)-\mathrm{MCPG}$ in blocking PI hydrolysis either produced by expressed group I mGluRs (Brabet et al., 1995) or measured in brain tissue (Littman and Robinson, 1994) depends on the agonist and is greater when $(1 S, 3 R)$-ACPD, rather than glutamate, is used. We found that $(S)$-MCPG was more potent in reversing $(1 S, 3 R)$-ACPDinduced IPSC reduction than in reducing DSI. Indeed, Littman and Robinson (1994) show that $3 \mathrm{~mm}(S)$-MCPG reduced L-glutamate-induced PI hydrolysis in hippocampal tissue suspensions by only $\sim 20 \%$, in good agreement with our data on DSI. Although $(S)$-MCPG antagonizes both group I and group III mGluRs (Manzoni et al., 1995) the evidence against group III mGluR involvement makes a role for group I mGluRs in DSI more likely. Alternatively, an undefined mGluR subtype could mediate the inhibition of interneurons. The signal could be a glutamate analog, and not glutamate itself. In any case, the block of DSI by $(S)$-MCPG suggests that a glutamate-like substance plays a role.

Additional tests of the mGluR hypothesis were based on previously established properties of DSI that should be duplicated by any putative DSI signal in CA1. The candidate mechanism should (1) not affect mIPSCs (Pitler and Alger, 1994; Alger et al., 1996), (2) be blocked by agents that block G-proteins, such as pertussis toxin (Pitler and Alger, 1994) or NEM (Morishita et al., 1997), (3) be reduced by bath application of $50 \mu \mathrm{M} 4-\mathrm{AP}$, and (4) not alter PPD (Alger et al., 1996; Morishita and Alger, 1997a). As assessed by these criteria, mGluR activation is a candidate mechanism for DSI induction. The $\mathrm{K}^{+}$channel blocker 4-AP reversed the depressant action of $(1 S, 3 R)$-ACPD on CA1 IPSCs and decreased DSI. [4-AP prevents the trans-ACPD-induced depression of EPSCs in cortical neurons (Sladeczek et al., 1993), suggesting that 4-AP sensitivity may be a general property of mGluR-mediated synaptic depression.] The sulfhydryl alkylating agent, NEM, enhances IPSCs and abolishes DSI (Morishita et al., 1997), and NEM abolishes the depressant action of (1S,3R)ACPD on IPSCs, implying that G-proteins are involved in both responses (cf. Shapiro et al., 1994).

$(1 S, 3 R)$-ACPD, like DSI, reduced IPSCs without affecting PPD of IPSCs, whereas many mechanisms that reduce transmitter release do affect PPD (Davies et al., 1990; Misgeld et al., 1995; Alger et al., 1996) by altering the probability of transmitter release by the first pulse according to the inverse relationship between probability of release by the first and second pulses of a pair (Martin, 1977). When evoked GABA release is decreased by substituting $\mathrm{Sr}^{2+}$ for extracellular $\mathrm{Ca}^{2+}$, PPD changes to pairedpulse facilitation (PPF) (Morishita and Alger, 1997a). Neither PPD nor $\mathrm{Sr}^{2+}$-induced PPF changed during DSI; thus the DSI process does not lower the probability of release at presynaptic terminals as other agents do. Baskys and Malenka (1991) found that $(1 S, 3 R)$-ACPD enhanced paired-pulse EPSC facilitation while depressing EPSCs, raising the possibility that $(1 S, 3 R)$ ACPD may suppress glutamate and GABA release via different mechanisms, although the effect on EPSCs was present only in young animals $(<30 \mathrm{~d})$. Barnes-Davies and Forsythe (1995) reported that $(1 S, 3 R)$-ACPD reduced EPSCs at the calyx of Held in rat auditory brainstem slices without affecting PPF or the presynaptic action potential. Subsequently, Takahashi et al. (1996) showed that $(1 S, 3 R)$-ACPD reduced $\mathrm{Ca}^{2+}$ entry into the calyx. It recently has been reported that a DSI-like process occurs in a dissociated hippocampal cell culture (Ohno-Shosaku et al., 1998). Despite having many similarities to DSI in the hippocampal slice, DSI in tissue culture altered the paired-pulse ratio. Why some forms of presynaptic inhibition alter paired-pulse release 


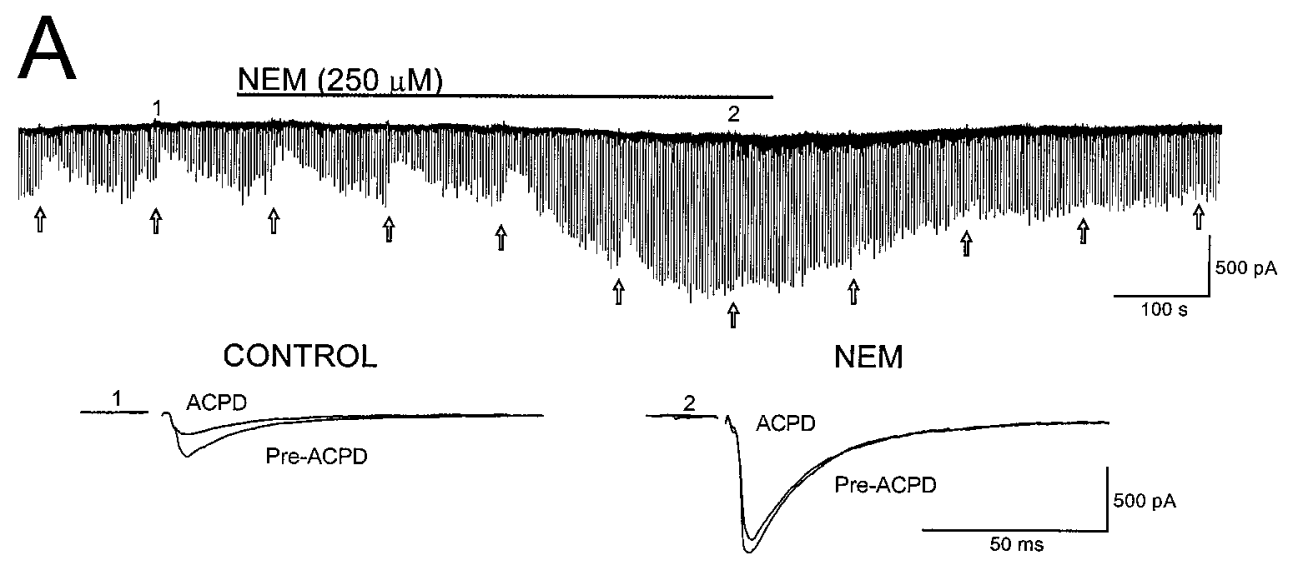

$\mathrm{B}_{1}$

4-AP $(50 \mu \mathrm{M})$
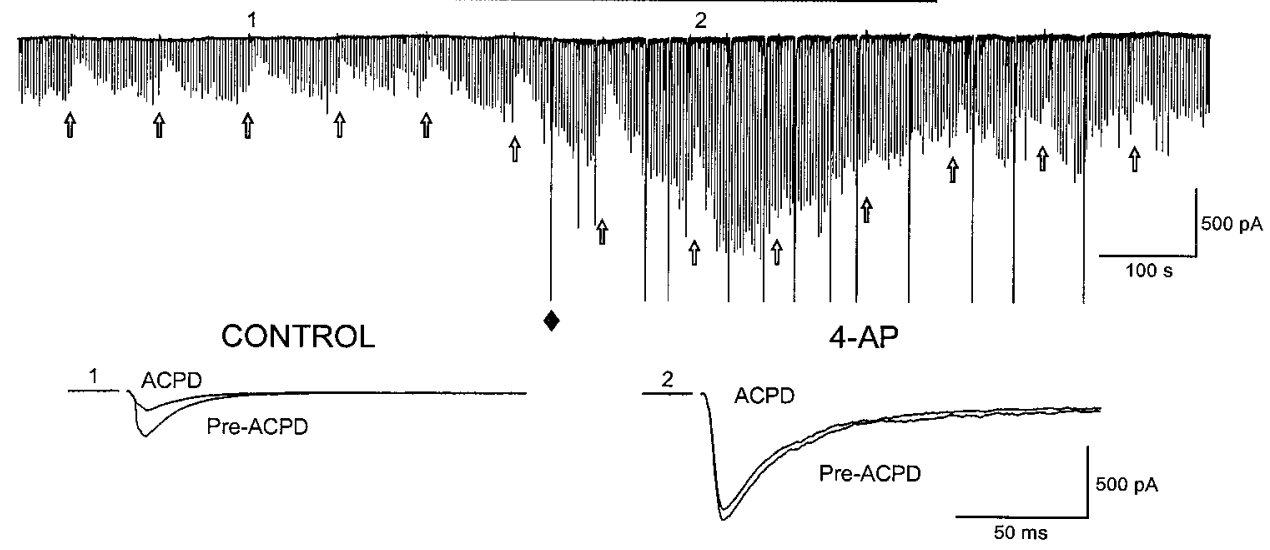

$\mathrm{B}_{2}$

4-AP $(50 \mu \mathrm{M})$

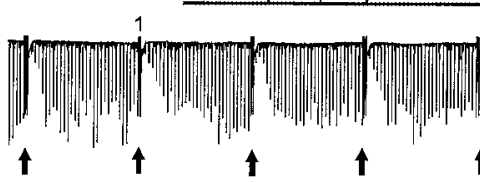

1

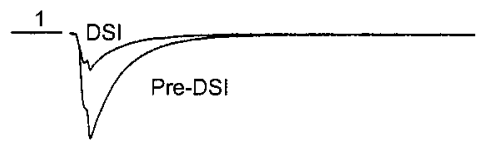

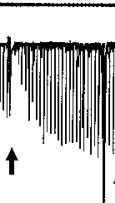
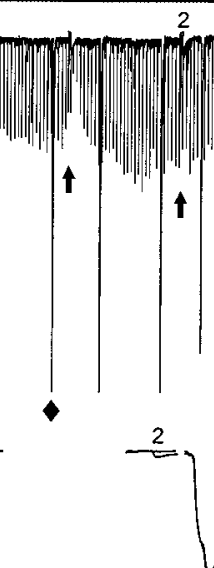
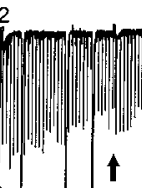
DSI

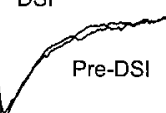

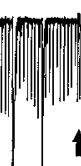
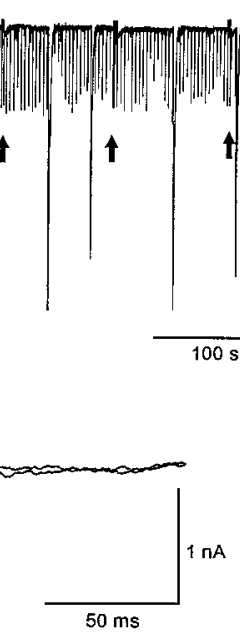

Figure 7. Agents that block DSI also block $(1 S, 3 R)$-ACPD-induced depression of evoked monosynaptic IPSCs. $A$, $\mathrm{N}$-ethylmaleimide (NEM; duration of application is indicated by the solid line) blocks IPSC suppression induced by iontophoretic application of $(1 S, 3 R)$ ACPD (open arrows). Below the current trace are IPSCs recorded before (Pre$A C P D)$ and after $(A C P D)$ iontophoresis of $(1 S, 3 R)$-ACPD at the indicated time points before (CONTROL) and during (NEM) application of NEM. $B_{1}$, $(1 S, 3 R)$-ACPD-induced depression of IPSCs is blocked by 4-aminopyridine (4-AP; duration of application is denoted by the solid line). IPSCs shown below the continuous trace were taken at the indicated time points. 4-AP induced large spontaneous inward currents (e.g., filled diamond), presumed to be $\mathrm{GABA}_{\mathrm{D}}$ responses (Perrault and Avoli, 1992). $B_{2}$, 4-AP blocks DSI of evoked IPSCs. IPSCs below the continuous trace were taken before (Pre-DSI) and after $(D S I)$ the depolarizing steps at the indicated time points. Individual IPSCs in $A$ and $B$ are averages of five consecutive IPSCs. Iontophoresis of $(1 S, 3 R)$-ACPD (25 mM) in $A$ and $B_{1}$ was accomplished by a $-155 \mathrm{nA}, 2 \mathrm{sec}$ current. Large spontaneous inward currents in $B_{2}$ are truncated to fit the figure. and others do not is unknown. In CA1, mGluR activation and DSI are similar in this regard, however.

Activation of mGluR can reduce voltage-dependent $\mathrm{Ca}^{2+}$ currents (Lester and Jahr, 1990; Sahara and Westbrook, 1993; Takahashi et al., 1996). DSI is dependent on $\mathrm{Ca}^{2+}$ influx into the pyramidal cell through voltage-dependent $\mathrm{Ca}^{2+}$ channels (Lenz et al., 1997), and thus mGluR agonists could reduce DSI by decreasing postsynaptic $\mathrm{Ca}^{2+}$ influx. On the other hand, the mGluR-induced inhibition of $\mathrm{Ca}^{2+}$ currents is dependent on postsynaptic G-proteins (Lester and Jahr, 1990; Sahara and West- 


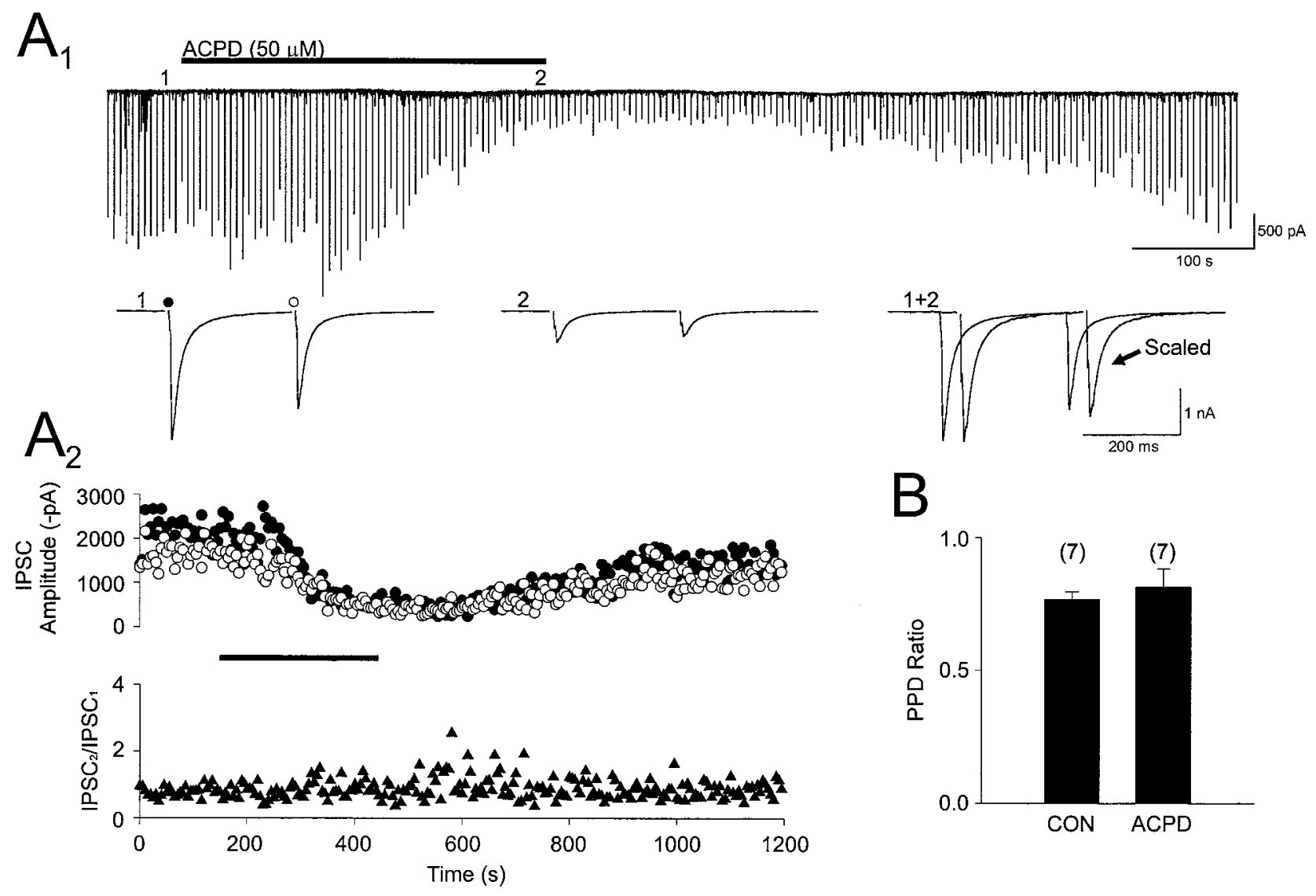

Figure 8. (1S,3R)-ACPD does not significantly alter paired-pulse depression of evoked monosynaptic IPSCs. $A_{1}$, Continuous trace illustrating the effects of bath-applied $(1 S, 3 R)$-ACPD (duration of application is indicated by the solid bar) on paired-pulse depression (PPD) of IPSCs. Pairs of IPSCs were elicited every $5 \mathrm{sec}$ with an interstimulus interval of $200 \mathrm{msec}$. Below the continuous trace are IPSCs elicited by the first (filled circle) and second (open circle) stimulus of the paired-pulse stimulation recorded at the indicated time points. In the right records the traces at 1 and 2 are overlapped (offset for ease of comparison) after the first IPSC in 2 was scaled up to match the amplitude of the first IPSC in 1. Note that the ratio of second to first IPSCs does not change in $(1 S, 3 R)$-ACPD. $A_{2}$, Plots generated from the experiment in $A_{1}$ illustrating the amplitudes of IPSCs arising from the first ( filled circles) and second (open circles) stimulus and corresponding PPD ratio (IPSC2/IPSC1, filled triangles). $B$, Average PPD ratio obtained from seven cells recorded in control and then in the presence of $(1 S, 3 R)$-ACPD. The IPSCs illustrated in $A_{1}$ are averaged from five consecutive IPSC pairs.

brook, 1993), and neither the (1S,3R)-ACPD-induced IPSC reduction nor occlusion of DSI requires GTP in the recording electrode. Thus mGluR effects on DSI probably are not caused by a reduction in $\mathrm{Ca}^{2+}$ influx, although we cannot rule out a contribution of this mechanism.

If a group I mGluR is involved in DSI and ( $1 S, 3 R)$-ACPDinduced IPSC suppression, it is more likely to be mGluR5 than mGluR1. Expression of mGluR1 mRNA in CA1 is low (Testa et al., 1994) and antibody staining for mGluR1 is confined to a discrete group of interneurons near the border of s. oriens and the CA1 alveus, whereas expression of mGluR5 mRNA is very high and antibody staining is dense and widely distributed in CA1. $(S)$-MCPG was somewhat less potent in blocking mGluR5ainduced than mGluR1a-induced PI hydrolysis in LLC-PKI cells when glutamate was the agonist (Brabet et al., 1995); when $(1 S, 3 R)$-ACPD was the agonist, $(S)$-MCPG was very effective at both receptors. In contrast, $4 \mathrm{CPG}$ was a potent antagonist of $(1 S, 3 R)$-ACPD actions only on mGluR1a-, not mGluR5a-, mediated effects; thus the combination of $(1 S, 3 R)$-ACPD and $4 C P G$ can distinguish between mGluR1a and mGluR5. Because IPSC suppression by $(1 S, 3 R)$-ACPD was blocked by $(S)$-MCPG, but not by $4 \mathrm{CPG}$, mGluR5 receptors may inhibit GABA release in CA1.
Results of ultrastructural labeling studies have been inconsistent regarding the localization of group I mGluRs, with one study finding evidence for axonal localization of group I mGluRs (Romano et al., 1995) and the other not (Shigemoto et al., 1997). If group I mGluRs are not present on or near inhibitory nerve terminals, the group I mGluRs known to exist on the somata and dendrites of the interneurons could be responsible for the effects we report.

\section{Implications of mGluR involvement in DSI}

The hypothesis that glutamate acting via mGluRs is the retrograde signal in hippocampal CA1 DSI can explain some puzzles. In cerebellum there are two types of DSI (Alger and Pitler, 1995). One acts on TTX-insensitive mIPSCs; the other is blocked when TTX is applied. Because TTX blocks CA1 DSI, we infer that DSI in CA1 and the second form of cerebellar DSI are identical. We suggest that glutamate, or an analog, could be the universal DSI messenger. The different types of DSI would be determined by the classes of mGluR on the interneurons and the effector mechanisms to which they are coupled. The group II mGluRs would be linked to the cAMP-dependent mechanism, which can block even TTX-insensitive mIPSCs. The mGluRs hypothetically responsi- 
ble for CA1 DSI instead would be linked to other mechanisms such that only TTX-sensitive release processes are affected.

A simple model for our results is that glutamate, released from pyramidal cell somatic-dendritic regions, acts directly on interneurons. Lledo et al. (1998) report that a vesicle-fusiondependent process presumably in pyramidal cell somaticdendritic regions is required for LTP. If glutamate were packaged in vesicles in the dendrites, then this process also could be involved in DSI. Alternatively, glutamate also can be released from glial cells (Barres, 1991; Parpura et al., 1994) and affect neuronal neurotransmitter release via mGluRs (Arague and Haydon, 1997). An unknown signal from pyramidal cells could induce glutamate release from glial cells or the numerous glutamatecontaining terminals of nearby excitatory fibers and mediate DSI indirectly. It will be important to test these implications of the mGluR hypothesis for DSI.

\section{REFERENCES}

Alger BE, Pitler TA (1995) Retrograde signaling at $\mathrm{GABA}_{\mathrm{A}}$ receptor synapses in the mammalian CNS. Trends Neurosci 18:333-340.

Alger BE, Pitler TA, Wagner JJ, Martin LA, Morishita W, Kirov SA, Lenz RA (1996) Retrograde signaling in depolarization-induced suppression of inhibition in rat hippocampal CA1 cells. J Physiol (Lond) 496:197-209.

Alger BE, Morishita W, Kirov SA (1997) Evaluation of glutamate as the retrograde signal in hippocampal CA1 DSI. Soc Neurosci Abstr 23:10.

Arague A, Haydon PG (1997) Astrocytes modulate evoked synaptic transmission between cultured hippocampal neurons. Soc Neurosci Abstr 23:359.

Barnes-Davies M, Forsythe ID (1995) Pre- and postsynaptic glutamate receptors at a giant excitatory synapse in rat auditory brainstem slices. J Physiol (Lond) 488:387-406.

Barres BA (1991) New roles for glia. J Neurosci 11:3685-3694.

Baskys A, Malenka RC (1991) Agonists at metabotropic glutamate receptors presynaptically inhibit EPSCs in neonatal rat hippocampus. J Physiol (Lond) 444:687-701.

Blanton MG, Lo Turco JJ, Kriegstein AR (1989) Whole-cell recording from neurons in slices of reptilian and mammalian cerebral cortex. J Neurosci Methods 30:203-210.

Brabet I, Mary S, Bockaert J, Pin J-P (1995) Phenylglycine derivatives discriminate between mGluR1- and mGluR5-mediated responses. Neuropharmacology 34:895-903.

Capogna M, Gähwiler BH, Thompson SM (1995) Presynaptic enhancement of inhibitory synaptic transmission by protein kinases $\mathrm{A}$ and $\mathrm{C}$ in the rat hippocampus in vitro. J Neurosci 15:1249-1260.

Conn PJ, Boss V, Chung DS (1994) Second-messenger systems coupled to metabotropic glutamate receptors. In: The metabotropic glutamate receptors (Conn PJ, Patel J, eds), pp 59-98. Totowa, NJ: Humana.

Davies CH, Davies SN, Collingridge GL (1990) Paired-pulse depression of monosynaptic GABA-mediated inhibitory postsynaptic responses in rat hippocampus. J Physiol (Lond) 424:513-531.

Desai MA, McBain CJ, Kauer JA, Conn PJ (1994) Metabotropic glutamate receptor-induced disinhibition is mediated by reduced transmission at excitatory synapses onto interneurons and inhibitory synapses onto pyramidal cells. Neurosci Lett 181:78-82.

Gereau IV RW, Conn PJ (1995a) Multiple presynaptic metabotropic glutamate receptors modulate excitatory and inhibitory synaptic transmission in hippocampal area CA1. J Neurosci 15:6879-6889.

Gereau IV RW, Conn PJ (1995b) Roles of specific metabotropic glutamate receptor subtypes in regulation of hippocampal CA1 pyramidal cell excitability. J Neurophysiol 74:122-129.

Glitsch M, Llano I, Marty A (1996) Glutamate as a candidate retrograde messenger at interneurone-Purkinje cell synapses of rat cerebellum. J Physiol (Lond) 497:531-537.

Ito I, Kohda A, Tanabe S, Hirose E, Hayashi M, Mitsunaga S, Sugiyama H (1992) 3,5-Dihydroxyphenyl-glycine: a potent agonist of metabotropic glutamate receptors. NeuroReport 3:1013-1016.

Jouvenceau A, Dutar P, Billard J-M (1995) Presynaptic depression of inhibitory postsynaptic potentials by metabotropic glutamate receptors in rat hippocampal CA1 pyramidal. Eur J Pharmacol 281:131-139.

Kamiya H, Shinozaki H, Yamamoto C (1996) Activation of metabo- tropic glutamate receptor type $2 / 3$ suppresses transmission at rat hippocampal mossy fibre synapses. J Physiol (Lond) 493:447-455.

Kavalali ET, Zhuo M, Bito H, Tsien RW (1997) Dendritic $\mathrm{Ca}^{2+}$ channels characterized by recordings from isolated hippocampal dendritic segments. Neuron 18:651-663.

Lambert NA, Teyler TJ (1991) Adenosine depresses excitatory, but not fast inhibitory, synaptic transmission in area CA1 of the rat hippocampus. Neurosci Lett 122:50-52.

Lenz RA, Wagner JJ, Alger BE (1997) Involvement of N- and L-type

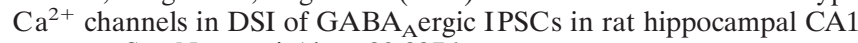
neurons. Soc Neurosci Abstr 23:2276.

Lester RAJ, Jahr CE (1990) Quisqualate receptor-mediated depression of calcium currents in hippocampal neurons. Neuron 4:741-749.

Littman L, Robinson MB (1994) The effects of L-glutamate and trans(+)-1-amino-1,3-cyclopentanedicarboxylate on phosphoinositide hydrolysis can be pharmacologically differentiated. J Neurochem 63:1291-1302.

Llano I, Marty A (1995) Presynaptic metabotropic glutamatergic regulation of inhibitory synapses in rat cerebellar slices. J Physiol (Lond) 486:163-176.

Llano I, Leresche N, Marty A (1991) Calcium entry increases the sensitivity of cerebellar Purkinje cells to applied GABA and decreases inhibitory synaptic currents. Neuron 6:565-574.

Lledo P-M, Zhang X, Sudhof TC, Malenka RC, Nicoll RA (1998) Postsynaptic membrane fusion and long-term potentiation. Science 279:399-403.

Manzoni OJ, Castillo PE, Nicoll RA (1995) Pharmacology of metabotropic glutamate receptors at the mossy fiber synapses of the guinea pig hippocampus. Neuropharmacology 34:865-871.

Martin AR (1977) Junctional transmission. II. Presynaptic mechanisms. In: Handbook of physiology, Sec 1, The nervous system, Vol I, Pt 1 (Kandel ER, ed), pp 329-355. Bethesda, MD: American Physiological Society.

Misgeld U, Bijak M, Jarolimek W (1995) A physiological role for $\mathrm{GABA}_{\mathrm{B}}$ receptors and the effects of baclofen in the mammalian central nervous system. Prog Neurobiol 46:423-462.

Morishita W, Alger BE (1997a) $\mathrm{Sr}^{2+}$ supports DSI and provides new evidence for a presynaptic expression mechanism in rat hippocampal slices. J Physiol (Lond) 505:307-317.

Morishita W, Alger BE (1997b) Differential effects of type II mGluR

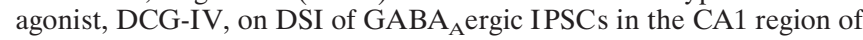
rat hippocampus in vitro. Soc Neurosci Abstr 23:356.

Morishita W, Kirov SA, Pitler TA, Martin LA, Lenz RA, Alger BE (1997) $N$-ethylmaleimide blocks depolarization-induced suppression of inhibition and enhances GABA release in the rat hippocampal slice in vitro. J Neurosci 17:941-950.

Nicoll RA, Alger BE (1981) A simple chamber for recording from submerged brain slices. J Neurosci Methods 4:153-156.

Ohno-Shosaku T, Sawada S, Yamamoto C (1998) Properties of depolarization-induced suppression of inhibitory transmission in cultured rat hippocampal neurons. Pflügers Arch 435:273-279.

Okamoto N, Hori S, Akazawa C, Hayashi Y, Shigemoto R, Mizuno N, Nakanishi S (1994) Molecular characterization of a new metabotropic glutamate receptor mGluR7 coupled to inhibitory cyclic AMP signal transduction. J Biol Chem 269:1231-1236.

Parpura V, Basarsky TA, Liu F, Jeftinija K, Jeftinija S, Haydon PG (1994) Glutamate-mediated astrocyte-neuron signalling. Nature 369:744-747.

Perrault P, Avoli M (1992) 4-Aminopyridine-induced epileptiform activity and a GABA-mediated long-lasting depolarization in the rat hippocampus. J Neurosci 12:104-115.

Pin J-P, Duvoisin R (1995) The metabotrophic glutamate receptors: structure and function. Neuropharmacology 34:1-26.

Pitler TA, Alger BE (1992) Postsynaptic spike firing reduces synaptic $\mathrm{GABA}_{\mathrm{A}}$ responses in hippocampal pyramidal cells. J Neurosci 12:4122-4132.

Pitler TA, Alger BE (1994) Depolarization-induced suppression of GABAergic inhibition in rat hippocampal pyramidal cells: G-protein involvement in a presynaptic mechanism. Neuron 13:1447-1455.

Poncer J-C, Shinozaki H, Miles R (1995) Dual modulation of synaptic inhibition by distinct metabotropic glutamate receptors in the rat hippocampus. J Physiol (Lond) 485:121-134.

Romano C, Sesma MA, McDonald CT, O'Malley K, van den Pol AN, Olney JW (1995) Distribution of metabotropic glutamate receptor mGluR5 immunoreactivity in rat brain. J Comp Neurol 355:455-469. 
Sahara Y, Westbrook GL (1993) Modulation of calcium currents by a metabotropic glutamate receptor involves fast and slow kinetic components in cultured hippocampal neurons. J Neurosci 13:3041-3050.

Saugstad JA, Kinzie JM, Mulvihill ER, Segerson TP, Westbrook GL (1994) Cloning and expression of a new member of the L-2-4phosphonobutyric acid-sensitive class of metabotropic glutamate receptors. Mol Pharmacol 45:367-372.

Schoepp DD (1994) 3,5-Dihydroxyphenylglycine is a highly selective agonist for phosphoinositide-linked metabotropic glutamate receptors in the rat hippocampus. J Neurochem 63:769-772.

Shapiro MS, Wollmuth LP, Hille B (1994) Modulation of $\mathrm{Ca}^{2+}$ channels by PTX-sensitive G-proteins is blocked by $N$-ethylmaleimide in rat sympathetic neurons. J Neurosci 14:7109-7116.

Shigemoto R, Kinoshita A, Wada E, Nomura S, Ohishi H, Takada N, Flor PJ, Neki A, Abe T, Nakanishi S, Mizuno N (1997) Differential presynaptic localization of metabotropic glutamate receptor subtypes in the rat hippocampus. J Neurosci 17:7503-7522.

Sladeczek F, Momiyama A, Takahashi T (1993) Presynaptic inhibitory action of a metabotropic glutamate receptor agonist on excitatory transmission in visual cortical neurons. Proc R Soc Lond [Biol] 253:297-303.

Suzdak PD, Thomsen C, Mulvihill E, Kristensen P (1994) Molecular cloning, expression, and characterization of metabotropic glutamate receptor subtypes. In: The metabotropic glutamate receptors (Conn PJ, Patel J, eds), pp 1-30. Totowa, NJ: Humana.

Swartz KJ, Bean BP (1992) Inhibition of calcium channels in rat CA3 pyramidal neurons by a metabotropic glutamate receptor. J Neurosci $12: 4358-4371$.

Takahashi T, Forsythe ID, Tsujimoto T, Barnes-Davies M, Onodera K (1996) Presynaptic calcium current modulation by a metabotropic glutamate receptor. Science 274:594-597.

Testa CM, Catania MV, Young AB (1994) Anatomical distribution of metabotropic glutamate receptors in mammalian brain. In: The metabotropic glutamate receptors (Conn PJ, Patel J, eds), pp 99-123. Totowa, NJ: Humana.

Trombley PQ, Westbrook GL (1992) L-AP4 inhibits calcium currents and synaptic transmission via a G-protein-coupled glutamate receptor. J Neurosci 12:2043-2050.

Vincent P, Marty A (1993) Neighboring cerebellar Purkinje cells communicate via retrograde inhibition of common presynaptic interneurons. Neuron 11:885-893.

Vincent P, Armstrong CM, Marty A (1992) Inhibitory synaptic currents in rat cerebellar Purkinje cells: modulation by postsynaptic depolarization. J Physiol (Lond) 456:453-471. 